\title{
A vueltas con la desconexión digital: eficacia y garantías de lege lata.
}

\section{Again with right to digital disconnection: effectiveness and current guarantees}

\author{
Juan Antonio Altés Tárrega* \\ Profesor Titular de Derecho del Trabajo y de la Seguridad Social \\ Universitat de València. Estudi General
}

ORCID ID: 0000-0003-1530-8545

Sergio Yagüe Blanco ${ }^{* * *}$

Personal Investigador en Formación Predoctoral de Derecho del Trabajo y de la Seguridad Social ${ }^{* * *}$ Universitat de València. Estudi General

ORCID ID: 0000-0002-7420-516X

Recibido: 5/2/2020

Aceptado: 23/3/2020

doi: https://doi.org/10.20318/labos.2020.5539

Resumen: $\quad$ Mediante el presente estudio tratamos de reconstruir y analizar el régimen jurídico de la "desconexión digital" a partir de los escasos datos normativos y de las aportaciones doctrinales precedentes. Nuestra postura parte de la tesis de que, a pesar de que la labor del legislador orgánico no ha sido impecable, todavía la regulación cuenta con un margen interpretativo desde el que puede reivindicarse su efectividad para garantizar la tutela de los derechos laborales imbricados. En fin, incorporamos una breve aproximación a la desconexión en relación con el teletrabajo habida cuenta de su mayor implantación desde el comienzo de la crisis del COVID-19.

Palabras clave: desconexión digital, tiempo de trabajo, seguridad y salud laboral, teletrabajo, derechos fundamentales.

Abstract: $\quad$ Through this study we try to reconstruct and analyze the legal regime of the right to digital disconnection from his weak regulation and the preceding doctrinal contributions. Our position starts from the thesis that, although the work of the legislator has not been impeccable, the regulation still has an interpretati-

\footnotetext{
*Este trabajo se ha desarrollado en el marco del Proyecto de investigación autonómico "Mi jefe es un algoritmo: Los efectos de la reputación online y la inteligencia artificial en el trabajo en plataformas digitales" (GV/2019/164), cuyo investigador principal es el Prof. Adrián Todolí Signes.

"juan.a.altes@uv.es

*** sergio.yague@uv.es

${ }^{* * * *}$ Contrato financiado por el Ministerio de Ciencia, Innovación y Universidades para la Formación de Profesorado Universitario (FPU 2015).
} 
ve margin from which its effectiveness can be claimed to guarantee the protection of embedded labor rights.

Finally, we incorporate a brief approach to disconnection in relation to teleworking, given its greater implementation since the beginning of the COVID-19 crisis.

Keywords: digital disconnection, working time, occupational health, teleworking, fundamental rights.

\section{Consideraciones previas}

La actual interconectividad digital facilita la gestión empresarial. El empresario dispone de medios más efectivos que agilizan y hacen más eficientes las prestaciones de servicios, al permitir una monitorización continua de las mismas. Efectivamente, los ordenadores, tablets, smartphones o cualquier otro dispositivo informático con acceso a la red poseen múltiples herramientas (sistemas de video, geolocalización, sistemas de mensajería...) que posibilitan la comunicación con el trabajador y su control en cualquier momento y lugar. Las ventajas de su uso en el entorno laboral son evidentemente muchas, pero parece igualmente evidente que el mal uso o el abuso en su utilización puede suponer un riesgo psicosocial para la salud del trabajador y una intromisión empresarial en el tiempo de no trabajo.

Estar permanentemente conectados permite una mayor disponibilidad del trabajador y desdibuja las fronteras entre el tiempo de trabajo productivo, -en el que se encuentra bajo el poder de dirección y control del empresario- y el reproductivo -aquel que el trabajador decide como usa en función de sus intereses propios ${ }^{1}-$, ya que muchas tareas laborales se asumen, se encargan y se resuelven, apelando a la urgencia o a otras causas, fuera del horario y del lugar de trabajo ${ }^{2}$. En definitiva, la incorporación de las TICs a las relaciones de trabajo ha provocado un "hiperpresentismo" digital que constituye uno de los grandes retos actuales en materia de tiempo de trabajo ${ }^{3}$.

A fin de evitarlo, por todo el mundo han surgido iniciativas que establecen el derecho a la desconexión digital para que los trabajadores no sean molestados en su tiempo privado. Otros estudios han dado cuenta de este fenómeno global, relatando cómo grandes empresas han tomado medidas unilaterales para atajarlo y diversas intervenciones legislativas de este tipo en Corea del Sur, Filipinas, Alemania, Bélgica, Italia o Suiza que no siempre han llegado a buen puerto ${ }^{4}$.

\footnotetext{
${ }^{1}$ Molina Navarrete, Cristóbal. Jornada laboral y tecnologías de la info-comunicación: "desconexión digital”, garantía del derecho al descanso. Temas laborales: Revista andaluza de trabajo y bienestar social, Consejo Andaluz de Relaciones Laborales, $\mathrm{n}^{\circ} 138$, 2017, p. 254 y ss. En similar sentido, Cialti, Pierre-Henri. El derecho a la desconexión en Francia: ¿más de lo que parece? Temas laborales: Revista andaluza de trabajo y bienestar social, Consejo Andaluz de Relaciones Laborales, nº 137, 2017, p. 164; RodRíGUEZ Fernández, María Luz y Pérez del Prado, Daniel. El impacto de la economía 4.0 sobre las condiciones de trabajo y empleo. Estudio de caso en dos empresas de base tecnológica. Cuadernos de Relaciones Laborales, Universidad Complutense de Madrid, Vol. 36, no 2-extra, 2018, p. 358; TALÉNS Visconti, Eduardo. La desconexión digital en el ámbito laboral: un deber empresarial y una nueva oportunidad de cambio para la negociación colectiva. Revista de Información Laboral, Lex Nova, no 4, 2018, p. 2/12. Recurso electrónico recuperado el 02/03/19 de la BD Aranzadi.

${ }^{2}$ Esta situación es todavía más alarmante en el caso de las empresas de base tecnológica, en la que los estudios vienen demostrando que la prolongación del tiempo de trabajo es una constante en el sector [Rodríguez Fernández, María Luz y Pérez del Prado, Daniel. El impacto..., ob. cit., p. 367].

${ }^{3}$ Fernández Avilés, José Antonio. Cronorreflexión al hilo de cuestiones actuales sobre tiempo de trabajo. Revista de Trabajo y Seguridad Social-CEF, Centro de Estudios Financieros, no 421, 2018, p. 5.

${ }^{4}$ Sobre el tema Molina Navarrete, Cristóbal. El tiempo de los derechos en un mundo digital: ¿¿xiste un nuevo "derecho humano a la desconexión" de los trabajadores fuera de la jornada? Revista de la Facultad de Derecho de México, Tomo 68, no 269, 2017, pp. 904 y ss.; Molina Navarrete, Cristóbal. Jornada laboral..., ob. cit., pp. 254 y ss.; Naranjo Colorado, Luz Dary. Vicisitudes del nuevo derecho a la desconexión digital: un análisis desde la base del derecho laboral. Saber, ciencia y libertad, Universidad Libre, Vol. 12, no 2, 2017, pp. 51 y ss.
} 
Sin duda, la actuación más destacada, por pionera, es la regulación francesa de este derecho, aparecida en la LOI n ${ }^{\circ} 2016-1088$ du 8 août 2016 relative au travail, à la modernisation du dialogue social et à la sécurisation des parcours professionnels. No obstante, su relevancia no evitó que fuera criticada por establecer un derecho prácticamente vacío de contenido, esto es, un brindis al sol' Aunque como reflejan algunos estudios, este derecho ya se había incluido previamente en convenios colectivos tanto a nivel interprofesional, promoviendo que las empresas establezcan tiempos de desconexión para favorecer la conciliación laboral y familiar y promuevan un buen uso de las TICS ${ }^{6}$; así como sectorial, mediante cláusulas que obligan a la desconexión de las herramientas de comunicación remota, insisten en la necesidad de que la empresa respete los tiempos de no trabajo y recuerden a los trabajadores la no obligación de atender a estas solicitudes ${ }^{7}$; y, especialmente, a nivel empresarial, reconociendo el derecho a la desconexión de los trabajadores en relación con el derecho a la salud y la vida privada de los trabajadores y estableciendo mecanismos de control y seguimiento ${ }^{8}$.

En España la negociación colectiva reciente también ha empezado a hacerse eco del problema. En este sentido, el XVI Convenio Colectivo de la Empresa ONCE y su personal recoge este derecho en su Plan de Igualdad como medida para favorecer la conciliación laboral y familiar'. El Convenio Colectivo del Sector de Industria, Servicios e Instalaciones del Metal de la Comunidad de Madrid establece un compromiso para fomentar la desconexión digital ${ }^{10}$. También el Acuerdo Interprofesional de Cataluña para los años 2018-2020 propone que la negociación colectiva incorpore una cláusula sobre la desconexión digital, que las empresas elaboren un protocolo sobre el mismo, y la realización de campañas de sensibilización dirigidas a las plantillas, mandos intermedios y a la propia dirección de la empresa ${ }^{11}$. Por otro lado, a nivel de empresa el mayor revuelo mediático lo generó el Convenio colectivo del Grupo AXA (2017-2020) ${ }^{12}$, debido a que fue el primero en incluir entre su contenido normativo el derecho a la desconexión digital, reconociendo, "salvo causa de fuerza mayor o circunstancias excepcionales (...) el derecho de los trabajadores a no responder a los mails o mensajes profesionales fuera de su horario de trabajo"13. Otro ejemplo de similar alcance se encuentra en la cláusula del Convenio de la empresa Barcelona Cicle de l'Aigua, SA (BACSA, periodo 20172020), aunque rebaja el alcance del derecho al establecer que la empresa "procurará" que no sea necesaria la respuesta a llamadas ni mensajes ni la realización de conexiones fuera del horario ${ }^{14}$. Y, en fin, quizás con un grado de concreción algo mayor, el Convenio de la sucursal española de la empresa EUI Limited, en la medida en que "reconoce, alienta y espera la desconexión electrónica de sus trabajadores con la empresa

\footnotetext{
${ }^{5}$ Molina Navarrete, Cristóbal. Jornada laboral..., ob. cit., p. 253 y ss.; en el mismo sentido: Cialti, Pierre-Henri. El derecho a la desconexión..., ob. cit., p. 181; Alemán PÁez, Francisco. El derecho de desconexión digital. Trabajo y derecho: nueva revista de actualidad y relaciones laborales, Wolters Kluwer, no 30, 2017, pp. 11 y 14/29 y ss. Recurso electrónico recuperado el 02/03/18 de la BD Smarteca.

${ }^{6}$ El Acuerdo Nacional Interprofesional de 19 de junio de 2013 sobre la calidad de vida en el trabajo.

${ }^{7}$ Acuerdo Import-export (avenant du 27-06-2016) -Liaisons Sociales Quotidien- L'actualité no 17196 du 8 novembre 2016; y Commerces de gros (avenant du 30-06-2016) -Liaisons Sociales Quotidien- L'actualité no 17181 du 14 octobre 2016).

${ }^{8}$ Sobre la experiencia legal y convencional en Francia vid Cialti, Pierre-Henri. El derecho a la desconexión..., ob. cit., pp. 167 y ss.

${ }^{9}$ Resolución de 8 de enero de 2018, de la Dirección General de Empleo, por la que se registra y publica el XVI Convenio colectivo de la ONCE y su personal.

${ }^{10}$ Resolución de 14 de enero de 2019, de la Dirección General de Trabajo de la Consejería de Economía, Empleo y Hacienda.

${ }^{11}$ Resolución TSF/2053/2018, de 4 de septiembre, del Departamento de Trabajo, Asuntos sociales y familias de la Generalitat de Catalunya.

${ }^{12}$ Resolución de 21 de septiembre de 2017, de la Dirección General de Empleo.

${ }^{13}$ La doctrina ha manifestado que se trata de una regulación ambigua, poco precisa que no articula en realidad ningún derecho nuevo, ni obligación concreta lo que ha llevado a la consideración que se trata más de una mera declaración formal que de una construcción jurídica real - Molina Navarrete, Cristóbal. Jornada laboral..., ob. cit., pp. 251 y 252; TAlÉns Visconti, Eduardo. La desconexión digital..., ob. cit., pp. 10/12 y ss.

${ }^{14}$ Resolución de 19 de marzo de 2018, del Departamento de Trabajo, Asuntos sociales y familias de la Generalitat de Catalunya.
} 
fuera de sus horas de trabajo", mediante cualquier tecnología de comunicación y a fin de que la plantilla se dedique al desarrollo de sus intereses personales, privados y familiares ${ }^{15}$.

Pues bien, en este contexto, nuestro país ha asumido en la Ley Orgánica 3/2018, de 5 de diciembre, de Protección de Datos Personales y Garantía de los Derechos Digitales (en adelante LOPDP) la positivización de este derecho junto con otras garantías de los denominados "derechos digitales".

Llegados a este punto, debemos preguntarnos si la existencia de este derecho dependía de su expresa positivización. La doctrina que ha tratado esta materia ha respondido a esta pregunta de la misma manera: la ausencia de una regulación expresa no condiciona la existencia del derecho en base a la normativa ya existente ${ }^{16}$.

Desde luego, el derecho a no responder, como garantía al descanso, existía en nuestro ordenamiento jurídico con anterioridad a su plasmación legal. Nadie puede argumentar que, sin este reconocimiento, los trabajadores estuvieran constreńidos a responder al empresario, exponiéndose al poder disciplinario caso de no hacerlo ${ }^{17}$. La STC 192/2003, de 27 de octubre, dictada en materia de vacaciones, era taxativa en este sentido y su doctrina puede extenderse de forma general a otras situaciones. No se requiere la existencia de una norma concreta ante "la capacidad de los derechos fundamentales de los trabajadores de integrar prohibiciones para el empleador y derechos de autodeterminación para el trabajador en el ejercicio del poder de dirección extralimitado" ${ }^{18}$.

La doctrina judicial también ha entrado en el pasado a resolver las posibles extralimitaciones empresariales en relación con el uso de dispositivos digitales. Tal es el caso de la SAN, Social, de 17 de julio de 1997, Proc. 120/1997, en relación con la orden empresarial para que los trabajadores mantuvieran una conexión ininterrumpida de los teléfonos móviles de la empresa y de sus clientes, lo cual implicaría que los trabajadores tendrían que estar pendientes en las horas no coincidentes con la jornada de trabajo. Más recientemente, la STSJ Cataluña de 23 de mayo de 2013, Rec. 6212/2012, determinó que el uso de un dispositivo con GPS integrado en el teléfono móvil con que la empresa proporciona a los trabajadores con el fin de intervenir rápidamente en caso de accidente, que han de llevar consigo incluso en sus casas, pone a los trabajadores en una situación de in vigilando incluso en su ámbito de vida privada. En estos casos, aunque no se alude expresamente, se está valorando el derecho a la desconexión digital y resolviendo en consecuencia, aun sin una norma que lo sustentara expresamente como tal.

En definitiva, puede afirmarse que el marco normativo laboral de carácter genérico regulador del tiempo de trabajo (jornada, descansos, vacaciones, etc.) previsto en los artículos 34 y ss. del ET es más que suficiente para evitar que los trabajadores continúen trabajando más allá de los límites de la jornada laboral. Y de la misma manera, la normativa en materia de prevención de riesgos laborales también estaría prohibiendo este tipo de conductas empresariales por cuanto que vela por la protección de la seguridad y salud en el ámbito laboral, incluso en la modalidad de trabajo a distancia o teletrabajo (art. 13.4 ET). Así, el derecho a la desconexión digital no supone la creación de un "nuevo derecho" laboral, sino una concreción o manifestación expresa de otros ya existentes ${ }^{19}$.

\footnotetext{
${ }^{15}$ Resolución de 15 de junio de 2018, de la Consejería de Economía, Innovación, Ciencia y Empleo de la Junta de Andalucía”.

${ }^{16}$ Molina Navarrete, Cristóbal. Jornada laboral..., ob. cit., pp. 274 y ss.; Zamora, Santiago, 2019. Desconexión digital ¿̨novedad o anécdota?. En: Diario La Ley [en línea], no 9363. Recuperado el 03/03/2019 de https://diariolaley.laleynext.es/dll/2019/02/21/ desconexion-digital-novedad-o-anecdota.

${ }^{17}$ FernÁndez Avilés, José Antonio, señalaba con anterior a la LOPDP que "la solo aparente «anomia» legislativa" no puede dar lugar a "caer en la trampa de pensar que, sin su reconocimiento expreso, pueda existir -o siquiera sea admisible jurídicamente- una hipotética "obligación permanente de conexión", lo que equivaldría a una inaceptable obligación permanente de disponibilidad" [cfr. Cronorreflexión..., ob. cit., p. 15).

${ }^{18}$ Cfr. Molina Navarrete, Cristóbal. Jornada laboral..., ob. cit., p. 278.

${ }^{19}$ En este sentido, Cialti, Pierre-Henri. El derecho a la desconexión..., ob. cit., p. 180; Molina Navarrete, Cristóbal. El tiempo..., ob. cit., pp. 905 y ss.; Serrano Olivares, Raquel. Los derechos digitales en el ámbito laboral: comentario de urgencia a la ley orgánica 3/2018, de 5 de diciembre, de protección de datos personales y garantía de los derechos digitales. IUSLabor, Universitat
} 
Ahora bien, aunque esta normativa y la protección judicial dispensada resulta suficiente frente a la imposición de una norma o un pacto escrito por parte del empresario que sea abusivo, no resulta igual de eficaz ante otras situaciones más comunes, como la comunicación espontánea y constante materializada en mensajes, correos y llamadas que se suceden por goteo durante el tiempo de descanso ${ }^{20}$. Es por ello que mediante su reconocimiento se dota de eficacia a los derechos ya existentes $^{21}$. Su reconocimiento expreso en un mandato jurídico es positivo, en cuanto que pone de manifiesto la existencia de una conducta reiterada que la nueva dimensión tecnológica ha favorecido y está en la línea de la necesaria adaptación del Derecho del Trabajo a dicha situación ${ }^{22}$. De la misma manera, establecer un sistema de protección específico ha de considerarse igualmente positivo. Otra cosa es que la regulación establecida sea suficiente y cumpla con esta expectativa, como veremos en las siguientes páginas.

\section{La protección legal del derecho a la desconexión: el contenido del derecho y las obligaciones resultantes}

La LOPDPD, en vigor desde el 7 de diciembre de 2018, que actualiza el desarrollo del art. 18.4 CE, ha establecido en sus artículos 87 a 91 una serie de garantías en relación con los derechos digitales en el ámbito laboral ${ }^{23}$.

Además, fruto del reconocimiento legal de estos derechos se ha introducido un nuevo artículo 20 bis al Estatuto de los Trabajadores (DF 13 ${ }^{\text {a LOPDP) }}{ }^{24}$. En él se estipula que los "los trabajadores tienen derecho a la intimidad en el uso de los dispositivos digitales puestos a su disposición por el empleador, a la desconexión digital y a la intimidad frente al uso de dispositivos de videovigilancia y geolocalización en los términos establecidos en la legislación vigente en materia de protección de datos personales y garantía de los derechos digitales".

Resulta llamativa la ubicación sistemática elegida por el legislador para incorporar estos dere$\operatorname{chos}^{25}$. En efecto, no se ha optado por integrarlos en el art. 4.2 ET, entre los que poseen los trabajadores en la relación de trabajo, y que incluye expresamente los que tienen relevancia constitucional, sino a continuación del derecho empresarial a la dirección y control de la actividad laboral del art. 20 ET, configurándose como un aspecto más del mismo $^{26} \mathrm{o}$, más bien, una limitación a dichas

Pompeu Fabra, no 3, 2018, p. 226; Blázquez Agudo, Eva María. Novedades laborales en la nueva Ley orgánica de protección de datos. Trabajo y derecho: nueva revista de actualidad y relaciones laborales, Wolters Kluwer, no 50, 2019, p. 11/19. Recurso electrónico recuperado el 12/12/19 de la BD Smarteca.

${ }^{20}$ Taléns Visconti, Eduardo. La desconexión digital..., ob. cit., p. 5 y 6/12. En el mismo sentido, Tascón López, Rodrigo. El derecho de desconexión de los trabajadores (potencialidades en el ordenamiento español). Trabajo y derecho: nueva revista de actualidad y relaciones laborales, Wolters Kluwer, no 41, 2018, p.7/28. Recurso electrónico recuperado el 03/02/19 de la BD Smarteca.

${ }^{21}$ En este sentido, Molina Navarrete, Cristóbal. El tiempo..., ob. cit., pp. 906 y ss.; Vallecillo Gámez, María Rosa. El derecho a la desconexión: ¿"novedad digital" o esnobismo del "viejo" derecho al descanso. Revista de Derecho del Trabajo y Seguridad Social-CEF, Centro de Estudios Financieros, no 408, 2017, p. 173.

${ }^{22}$ En este sentido Alemán Páez, Francisco. El derecho de desconexión digital, ob. cit., pp. 9, 11 y 14/29.

${ }^{23}$ Para una visión completa del recorrido y la tramitación parlamentaria de la ley y de las iniciativas legislativas previas, véase: Barrios Baudor, Guillermo Leandro. El derecho a la desconexión digital en el ámbito laboral español: primeras aproximaciones. Revista Aranzadi Doctrinal, Thomson Reuters-Aranzadi, n. ${ }^{\circ}$ 1, 2019, pp. 4/18 a 10/18. Recurso electrónico recuperado el 12/12/19 de la BD Aranzadi.

${ }^{24}$ La Disposición Final 14a dispone la modificación del Estatuto Básico del Empleado Público para reconocer, con una redacción casi idéntica, estos mismos derechos a los empleados públicos previa incorporación de un apartado j) al art. 14 EBEP.

${ }^{25}$ En este sentido, Alemán Páez, Francisco. destaca la importancia de la ubicación sistemática. En relación a la ley francesa, que se ha insertado dentro del régimen jurídico previsto para los planes de igualdad, manifiesta que dicha ubicación condiciona el alcance de la desconexión y la concepción última del derecho [El derecho a la desconexión digital, ob. cit., pp. 13 y 15/29].

${ }^{26}$ Baylos Grau, Antonio. Los derechos digitales y la negociación colectiva. Diario La Ley, Wolters Kluwer, no 9331, 2019, p. 2/5. Recurso electrónico recuperado el 02/03/19 de la BD Smarteca. 
facultades empresariales. La opción legislativa no es intrascendente, sino que acarrea importantes consecuencias prácticas, pues, por ejemplo, no será aplicable la infracción específica prevista en la LISOS en relación con las vulneraciones de los derechos listados en el art. 4 ET.

En cualquier caso, para conocer el contenido de este derecho laboral a la desconexión digital es necesario acudir a la legislación en materia de protección de datos. Es el art. 88.1 LOPDP el que dispone que "los trabajadores y los empleados públicos tendrán derecho a la desconexión digital a fin de garantizar, fuera del tiempo de trabajo legal o convencionalmente establecido, el respeto de su tiempo de descanso, permisos y vacaciones, asi como de su intimidad personal y familiar".

Como puede observarse, el precepto, al igual que ocurre en los protocolos empresariales y convenios colectivos que dan cuenta del mismo, no define este derecho. Algún autor lo ha reflejado como "el derecho para el trabajador de no tener ningún contacto con herramientas digitales con su trabajo durante su tiempo de descanso y sus vacaciones" ${ }^{27}$. Esto abarcaría tanto la no recepción de comunicaciones o instrucciones fuera de la jornada de trabajo (mails, mensajes, llamadas, etc.), como la necesidad de evitar que el trabajador acabe prolongándola para realizar cualquier tarea relacionada con el trabajo gracias a las posibilidades de conectividad que ofrecen las NTICs ${ }^{28}$. Desde el punto de vista empresarial, sin embargo, cabría entenderlo como la prohibición de comunicarse o controlar a los trabajadores mediante dispositivos digitales durante los tiempos de descanso y vacaciones. Y, en fin, de forma neutra, implica el "apagado" de los dispositivos digitales fuera del tiempo de trabajo efectivo o en otros momentos en los que contractualmente haya que estar a disposición de la empresa.

A la luz de esta delimitación normativa es oportuno valorar dos aspectos: qué bienes jurídicos resultan protegidos y si la ley ha configurado la desconexión digital como un derecho del trabajador o una obligación empresarial. Como se verá, la determinación de los bienes jurídicos protegidos determina los distintos mecanismos de tutela aplicables, mientras que la segunda cuestión influye en las concretas medidas previstas para garantizar su eficacia.

\subsection{Los bienes jurídicos protegidos tras la LOPDP}

Determinar cuál es el bien jurídicamente protegido no es una cuestión meramente teórica, pues delimita el ámbito de actuación normativa para articular las garantías de este derecho. Por poner ejemplos, si consideramos que tutela el derecho a descanso, las instituciones reguladoras del tiempo de trabajo serán las que deban establecer los límites. Si se considera que el bien protegido es la seguridad y salud de los trabajadores, obliga a una relectura de las obligaciones impuestas por la Ley de Prevención de Riesgos Laborales (en adelante, LPRL), especialmente significativa habida cuenta de la falta de desarrollo reglamentario en materia de riesgos psicosociales. Por su parte, desde el ámbito de la conciliación de la vida laboral y familiar, se abren nuevas oportunidades de regulación en el seno de los planes de igualdad. De considerarse protegido un derecho fundamental pueden activarse los mecanismos de tutela contra la vulneración de los mismos. Y, en fin, en todos los casos, como se analizará, va a determinar la posibilidad de exigir unas u otras responsabilidades administrativas diferentes por su incumplimiento si encuentra acomodo en alguna de las previsiones de la Ley de Infracciones y Sanciones del Orden Social (en adelante, LISOS).

\footnotetext{
${ }^{27}$ Cfr. Cialti, Pierre-Henri. El derecho a la desconexión..., ob. cit., p. 165.

${ }^{28}$ Además de permitir múltiples de formas de comunicación, las NTICs y los medios técnicos existentes en la empresa (servidores, computación en la nube, redes de comunicación, etc.) dan acceso a otras tareas laborales como la realización de gestiones comerciales, elaboración de documentos, desarrollo de aplicaciones o mantenimiento de productos, etc. [VALLECILlo Gámez, María Rosa. El derecho a la desconexión..., ob. cit., p. 176].
} 
En especial, interesa concretar a qué derecho constitucional afecta, pues la tutela dispensada es distinta si se trata de un derecho fundamental, activándose en este caso unas garantías específicas.

Pues bien, en la regulación legal encontramos referencias a los derechos constitucionalmente protegidos que pueden resultar un tanto confusas y contradictorias. Precisamente por ello, con el fin de simplificar el análisis, conviene seguir la propia secuencia utilizada en el art. 88 LOPDP, que atribuye al derecho a la desconexión digital la finalidad de garantizar, por un lado, el tiempo de descanso, los permisos y las vacaciones; y, por otro lado, su intimidad personal y familiar.

La referencia al tiempo de trabajo conecta directamente con los derechos constitucionales al descanso y a la seguridad y salud de los trabajadores ${ }^{29}$, ambos principios rectores de la política social del Estado recogidos en el art. 40.2 CE. Y ello, a pesar de que el art. 88.1 LODP menciona el primero, pero omite el segundo, al menos, de forma directa, ya que efectúa una referencia a la fatiga informática en el apartado tercero. Con todo, la falta de una conexión expresa es llamativa, precisamente, por las implicaciones que tiene dicha conectividad que prolonga el tiempo de trabajo en la prevención de los riesgos psicosociales cuyo tratamiento había sido muy analizado por la doctrina. Efectivamente, el estrés laboral que conlleva la sobrecarga digital (fatiga digital o tecnoestrés) es un claro ejemplo de las consecuencias que puede acarrear el hecho de estar en conexión constante con el trabajo, pudiendo provocar burnt out o síndrome de desgaste profesional. Ambos derechos, la salud y el descanso del trabajador, están recogidos en el art. 31 de la Carta de Derechos Fundamentales de la Unión Europea bajo la rúbrica "condiciones de trabajo justas y equitativas". Sobre esta conexión no existe debate. Nadie duda que mediante la desconexión digital se pretende garantizar los derechos constitucionales al descanso y la protección de la salud ${ }^{30}$.

También entra en juego el derecho a la conciliación familiar y laboral, esto es, el derecho que poseen los trabajadores a compatibilizar el tiempo de trabajo con sus necesidades personales y familiares sin injerencias empresariales. Este derecho, aunque no está expresamente recogido en la Constitución, se deriva de sus artículos 14 y 39.3. Ciertamente, el texto legal no establece una relación directa con la conciliación de la vida laboral y familiar, aunque sí se alude a ella al establecerla como un objetivo a potenciar en la modalización del ejercicio de la desconexión digital en la negociación colectiva. La omisión de este derecho sorprende, en tanto que la ley francesa, en la que se basa, establece una fuerte relación entre la desconexión y la conciliación. De hecho, su regulación se inserta dentro de las cuestiones que obligatoriamente deben ser reguladas por la negociación colectiva en materia de igualdad de sexos, precisamente, para fomentar la conciliación de la vida laboral y personal.

Estos tres aspectos —el descanso, la conciliación y la prevención de riesgos psicosociales- se ponían de manifiesto en el denominado "Informe Mettling", encargado por el Ministerio de Trabajo francés, para evaluar las consecuencias de la transformación digital en el trabajo y que sirvió de inspiración a la normativa francesa ${ }^{31}$. Además, todas las intervenciones realizadas por la negociación colectiva en España se enmarcan en alguna de estas materias o en todas ellas.

Por otra parte, la referencia a la intimidad personal y familiar entronca este derecho con el de "vida privada", concepto que no se encuentra recogido en nuestra norma Constitución de forma expresa, pero que si lo está en otros tratados y convenios internacionales ratificados por Espańa, como, por ejemplo, la Declaración Universal de los Derechos Humanos de 1948, cuyo art. 12 es-

\footnotetext{
${ }^{29}$ En este sentido se han movido todas las aportaciones doctrinales. Entre otros: Molina NavarRETE, Cristóbal. Jornada laboral..., ob. cit., pp. 250 y ss.; VAllecillo Gámez, María Rosa. El derecho a la desconexión..., ob. cit., p. 177.

${ }^{30}$ Sobre todo, debe remitirse a todos los autores citados que analizaron el derecho a la desconexión con anterioridad a la aprobación de LOPDPGDD.

${ }^{31}$ Dicho informe, en realidad titulado "Transformación digital y vida en el trabajo" ("Transformation numérique et vie au travail”), es conocido así debido a su autor Bruno Mettling. Al respecto, tampoco parece suscitar dudas entre la doctrina [entre otros: Alemán PÁez, Francisco. El derecho de desconexión digital, ob. cit., p. 8/29].
} 
tablece que "nadie será objeto de injerencias arbitrarias en su vida privada, su familia, su domicilio o su correspondencia, ni de ataques a su honra o a su reputación..."; el Convenio Europeo de Derechos Humanos del Consejo de Europa, que, en su artículo 8, establece que "toda persona tiene derecho al respeto de su vida privada y familiar, de su domicilio y de su correspondencia"; y el art. 7 de la Carta de los Derechos Fundamentals de la Unión Europea que lo recoge prácticamente en estos mismos términos. Teniendo en cuenta que el art. 10.2 CE dispone que "las normas relativas a los derechos fundamentales y a las libertades que la Constitución reconoce, se interpretarán de conformidad con la Declaración Universal de Derechos Humanos y los tratados y acuerdos internacionales sobre las mismas materias ratificados por España", no cabe duda de que este derecho debe entenderse incluido en nuestra carta magna. No obstante, nuestra jurisprudencia constitucional ha trazado las líneas que llevan a delimitar este derecho.

Seguramente, el motivo de esta ausencia puede explicarse en base al uso indistinto durante mucho tiempo de los términos de intimidad y "vida privada". Sin embargo, actualmente, el derecho a la "vida privada" ha dejado de equipararse al derecho a la intimidad. Efectivamente, el derecho a la intimidad protege las facetas más íntimas de la persona y su círculo familiar, afectando a su "esfera espiritual, afectiva o intima" (STC 110/1984, de 26 de noviembre). Es decir, como ha manifestado el Tribunal Constitucional, lo que "el art. 18.1 garantiza es un derecho al secreto, a ser desconocido, a que los demás no sepan qué somos o lo que hacemos, vedando que terceros, sean particulares o poderes públicos, decidan cuáles sean los lindes de nuestra vida privada pudiendo cada persona reservarse un espacio resguardado de la curiosidad ajena, sea cual sea lo contenido en ese espacio" (entre otras: SSTC 127/2003, de 30 de junio; 199/2013, de 5 de diciembre). En contraposición, el concepto de "vida privada" se explicaría desde una dimensión más amplia, incluyendo otros aspectos de la vida personal que sobrepasan ese círculo íntimo. Doctrinalmente se ha afirmado que el derecho a la intimidad es un derecho fundamental integrado en una categoría dogmática más amplia que engloba también otros derechos de la personalidad: el derecho a la privacidad. El Tribunal Europeo de Derechos Humanos ha manifestado en diversas ocasiones sobre la esfera de protección de la vida privada que "sería demasiado restrictivo limitarla a un "círculo intimo" donde cada uno puede llevar su vida personal como quiera, y separarla totalmente del mundo exterior a este círculo. El respeto a la vida privada debe incluir también, en cierta medida, el derecho de los individuos para establecer $y$ desarrollar relaciones con sus semejantes" (STEDH 77/1992, de 16 de diciembre, Caso Niemietz contra Alemania). En este mismo sentido también se ha señalado que se refiere a aquellos factores relacionados la dignidad del individuo y su desarrollo personal (STEDH de 13 de febrero de 2003, Caso Odièvre contra Francia); y que "comprende la integridad física y psicológica de una persona y puede comprender múltiples aspectos de la identidad de la persona" (STEDH 2012, de 7 de febrero, Caso Axel Springer AG contra Alemania).

Así, el derecho a la vida privada protege aquellas facetas del individuo que, si bien de forma separada carecen de la relevancia de las que componen la esfera íntima, conjuntamente proporcionan un perfil completo del individuo. Datos como el nombre, la fecha de nacimiento, la imagen, las muestras biomédicas, el ADN y las huellas dactilares que permiten identificar a la persona —aun sin tratarse de información sensible que afecta a su esfera íntima- quedan comprendidos por la protección que dispensa el derecho a la vida privada. Por ello, la protección frente a las intromisiones informáticas y el derecho al tratamiento de datos personales también se incardinan claramente en este derecho. La conexión entre ambos derechos — vida privada y protección de datos- quedó plasmada en el art. 1 del Convenio 108 del Consejo de Europa, de 28 de enero de 1981, para la protección de las personas con respecto al tratamiento de datos de carácter personal, ratificado por España el 28 de enero de 1981. El TEDH se ha referido expresamente a esta cuestión (STEDH de 17 de diciembre de 2006, Caso B.B contra Francia), entendiendo que el derecho a la vida privada 
incluye los datos de carácter personal, es decir, en el sentir del art. 2 del Convenio 108 del Consejo de Europa, de 28 de enero de 1981, para la protección de las personas con respecto al tratamiento de datos de carácter personal es "toda información relativa a una persona física identificada o identifcable" (STEDH de 16 de febrero de 2000, Caso Amman contra Suiza).

A pesar de ello, en el seno de la Unión Europea el derecho a la protección de datos personales se desliga del derecho a la vida privada y se conforma como un derecho autónomo ${ }^{32}$. Algo similar ocurre en el derecho español. En efecto, el art. 18.4 CE recoge este derecho en relación con la obligación legal de limitar "el uso de la informática para garantizar el honor y la intimidad personal y familiar de los ciudadanos y el pleno ejercicio de sus derechos". Sin embargo, la primera sentencia que se refirió al derecho a la protección de datos (STC 254/1993, de 20 de julio) tomó como referente el art. 18.1 CE, esto es el derecho a la intimidad personal y no el art. 18.4 CE, de manera que hubo que esperar a la STC 290/2000, de 30 de noviembre y la STC 292/2000, de 30 de noviembre, para que el mismo fuera considerado como un derecho autónomo. En particular, ésta última resolución precisó que la libertad informática comprende tanto un derecho de contenido negativo, con el fin de excluir a terceros frente a intromisiones ilegítimas en la vida privada, como un derecho positivo a la protección de los datos con el fin de garantizar un poder de control y disposición sobre el uso y el destino de los datos personales para impedir su tráfico ilícito.

Puede entonces afirmarse que el derecho a la "vida privada" queda referenciado en el art. 18 CE y que los derechos allí expresados son concretas manifestaciones del mismo. El Tribunal Constitucional refrenda esta interpretación en la STC 292/2000, de 30 de noviembre, en la que entiende que, tanto la libertad informática, como el derecho a la intimidad comparten el mismo objetivo de ofrecer una eficaz protección a la vida privada personal y familiar, así como el mismo fundamento en los derechos a la dignidad y al libre desarrollo de la personalidad.

En atención a lo señalado hasta ahora, hay que discernir si el derecho a la desconexión digital en cuanto que incide sobre la "vida privada" afecta a alguno de estos derechos. Como señalábamos al principio de este apartado el 88 LOPDP hace referencia expresa al derecho a la intimidad personal y familiar. La propia exposición de motivos de esta norma manifiesta esta vinculación señalando que, dentro del Título X, "ocupa un lugar relevante el reconocimiento del derecho a la desconexión digital en el marco del derecho a la intimidad en el uso de dispositivos digitales en el ámbito laboral". También el nuevo art. 20 bis ET alude al derecho a la intimidad como derecho fundamental afectado, aunque una lectura detenida del precepto muestra cómo, intencionadamente o no, en realidad el respeto a la intimidad personal aparece como una garantía en relación al uso de dispositivos digitales y frente al uso de dispositivos de videovigilancia y geolocalización. Entre ambos, se reconoce el derecho a la desconexión digital sin mención alguna a la intimidad personal del trabajador ${ }^{33}$.

Pese a estas referencias legales y aunque algunos autores también aprecian cierta relación entre estos derechos ${ }^{34}$, a nuestro juicio, no parece que, con carácter general, la desconexión digital pueda subsumirse en la concepción relatada anteriormente del derecho a la intimidad personal y familiar. Ello no quiere decir que no existan situaciones excepcionales en que la conectividad con el

\footnotetext{
${ }^{32}$ Así venía considerado en la derogada Directiva 95/46/CE , en el Reglamento (UE) 2016/679 del Parlamento Europeo y del Consejo, de 27 de abril de 2016, relativo a la protección de las personas físicas en lo que respecta al tratamiento de datos personales y a la libre circulación de estos datos y por el que se deroga la Directiva 95/46/CE; y la Carta de Derechos Fundamentales de la Unión Europea, cuyo art. 8 señala que "toda persona tiene derecho a la protección de datos de carácter personal que la conciernan".

${ }^{33}$ Corrobora esta afirmación la redacción de la DF 14a LOPDPGDD que introduce en el artículo 14 del EBEP, un nuevo apartado j bis) por el que se reconocen idénticas garantías para los empleados públicos, pero con una redacción algo más clarificadora. Se reconoce el derecho de los empleados públicos "a la intimidad en el uso de dispositivos digitales puestos a disposición y frente al uso de dispositivos de videovigilancia y geolocalización, asi como a la desconexión digital en los términos establecidos en la legislación vigente en materia de protección de datos personales y garantía de los derechos digitales".

${ }^{34}$ Baylos Grau, Antonio. Los derechos digitales..., ob. cit., p. 4/5; Serrano Olivares, Raquel. Los derechos digitales..., ob. cit., p. 226; Barrios BaUdor, Guillermo Leandro. El derecho a la desconexión..., ob. cit., p. 10/18.
} 
trabajador fuera de la jornada sí revele datos íntimos personales ${ }^{35}$, pero no parece que la intención del legislador al concebir el derecho a la desconexión fuera tutelar al trabajador de este tipo de intromisiones.

Por otro lado, pese al silencio de la norma, podría pensarse que el derecho constitucional protegido es el de la protección de datos (art. 18.4 CE), habida cuenta de que el reconocimiento a la desconexión digital se ha llevado a cabo en el cuerpo normativo que regula dicha materia ${ }^{36}$. Sin embargo, tampoco apreciamos que encuentre acomodo en este derecho, en la medida en que las conductas empresariales frente a las que pretende articular sus garantías no se realizan, como regla general, con el objeto de obtener y mantener datos personales. Este aspecto es lo que diferencia y separa a la desconexión digital del resto de derechos digitales previstos en la LOPDP, que sí responden a la lógica de la protección de datos personales. Su inclusión en esta norma, a última hora y de forma desacertada, en lugar de incorporarlo en la regulación de la jornada de trabajo o en la LPRL resaltando así su carácter preventivo y su conexión con el derecho al descanso y a la salud ${ }^{37}$, obedece seguramente a razones de oportunidad ${ }^{38}$.

Tras descartar estas opciones, consideramos que los principales bienes constitucionales protegidos son el derecho al descanso, a la recuperación de la salud y a la conciliación de la vida familiar y que ha sido la inclusión del derecho de desconexión en la LOPDP lo que ha provocado que quede aparentemente más vinculado a la intimidad personal y a la propia protección de datos. Como senala el Tribunal Constitucional, una de las proyecciones constitucionales del derecho del trabajador a la protección y prevención de su salud se encuentra en el art. 15 de la CE que garantiza la "incolumidad corporal" frente la injerencias o agresiones de terceros y, en particular, frente a los riesgos del trabajo, de manera que se lesiona este derecho si no se respeta el derecho a una protección eficaz en materia de seguridad y salud en el trabajo en los términos del art. 14 LPRL (STC 62/2007, de 27 de marzo y STC 160/2007, de 2 de julio). Así, cabría plantear la posibilidad de acceder a la especial protección que se dispensa a los derechos fundamentales

Ahora bien, con ello no queremos decir que este derecho quede totalmente desligado del concepto de "vida privada". Ya hemos señalado que este concepto es más amplio del que se desprende de la suma de derechos relacionados en el art. $18 \mathrm{CE}$ y, en este sentido, no cabe duda que la desconexión digital tutela el derecho al descanso, entendido ahora como límite a las intromisiones por parte de la empresa fuera del tiempo de trabajo, esto es el derecho a mantener un espacio de vida privada al margen de la vida laboral ${ }^{39}$. Es más, esta interpretación a tenor de algún autor permitiría incluir el derecho en el art. 18.4 CE, entendiendo que el mismo no sólo se refiere a la protección de datos personales, sino también al derecho a no ser "molestado" mediante medios digitales en dicho tiempo de descanso ${ }^{40}$.

${ }^{35}$ Se ha puesto como ejemplo los casos en que el trabajador esté obligado a mantener videoconferencias fuera de su jornada y desde su domicilio, propiciando que se capten aspectos íntimos de su persona o de sus familiares (ej. creencias religiosas o políticas, determinadas circunstancias familiares, etc.). véase: Todolí Signes, Adrián. Nuevos derechos digitales incorporados al Estatuto de los Trabajadores y EBEP: Más dudas que novedades", En: Troncoso Reigada, Antonio, Comentarios al Reglamento General de Protección de Datos y a la Ley Orgánica de Protección de Datos de Carácter Personal y garantía de los Derechos Digitales, Civitas, preprint, p. 10/21.

${ }^{36}$ De hecho, resulta ciertamente sorprendente que este derecho no resulte nombrado en el art. 20 bis ET en relación con los derechos digitales de los trabajadores, ni en los distintos preceptos de la LOPDP, aunque si esta última ya refleja esta anomalía no es de extrañar que se haya trasladado al texto estatutario.

${ }^{37}$ TAléns Visconti, Eduardo. La desconexión digital..., ob. cit., p. 7/12,

${ }^{38}$ Igartua Miró, María Teresa. El derecho a la desconexión en la Ley orgánica 3/2018, de 5 de diciembre, de protección de datos personales y garantía de los derechos digitales. Revista de Trabajo y Seguridad Social-CEF, Centro de Estudios Financieros, $\mathrm{n}^{\circ}$ 432, 2019, pp., 71 y 72.

${ }^{39}$ En este sentido Molina Navarrete, C. afirma que "el derecho a la desconexión digital fuera de la jornada de trabajo forma parte del contenido esencial del derecho humano al respeto de la vida privada de toda persona, por supuesto también del trabajador" [Cfr. El tiempo, ob. cit., p. 918].

${ }^{40}$ Todolí Signes, Adrián. Nuevos derechos digitales..., ob. cit., p. 8/21. 
El hecho de que la desconexión digital no se relacione directamente con alguno de los derechos fundamentales recogidos en nuestra Constitución podría explicar la opción del legislador de derivar su desarrollo a la ley ordinaria (DF $1^{\text {a }}$ LOPDP $)^{41}$. En contra, otros autores han defendido la compatibilidad del carácter de ley ordinaria con el desarrollo de un verdadero derecho fundamental argumentando que la interpretación efectuada por el Tribunal Constitucional de la reserva de ley orgánica que realiza el texto constitucional para el desarrollo legislativo de los mismos abarca solo al desarrollo de aspectos esenciales de su régimen jurídico y, en todo caso, a las limitaciones que el legislador pueda realizar de las mismas (SSTC 173/1998, de 23 de julio; 101/1991, de 13 de mayo). En tanto en cuanto que el desarrollo no sea limitativo, nada obsta a que tenga el carácter de ley ordinaria aun cuando mediante la garantía a la desconexión digital se estuviera tutelando un Derecho Fundamental, cuestión que, como evidencian las consideraciones expuestas anteriormente, admite cierta discusión ${ }^{42}$. De esta manera, se ha afirmado, que se estaría facilitando su desarrollo tanto legal como por parte de la negociación colectiva, permitiendo garantizar un derecho de desconexión digital, aun cuando no se vea afectado el derecho a la vida privada o el de intimidad. Además, hay que tener en cuenta que los otros derechos implicados (al descanso y a la salud) no requieren ley orgánica para su desarrollo.

\subsection{La configuración del derecho en el art. 20 bis ET y 88.1 LOPDP}

Otra cuestión que ha centrado las opiniones de la doctrina tiene que ver con la configuración intrínseca de esta institución jurídica, bien como un derecho subjetivo del trabajador, lo que implica dotarle de la facultad de no responder, o bien como una obligación empresarial, es decir como una prohibición de estas prácticas empresariales.

Entendemos que la desconexión digital debe ser interpretada como una obligación empresarial. Implica una conducta de abstención por parte del empresario, ya que se extralimita en el uso de sus prerrogativas de dirección. Si se configura como un derecho del trabajador, es decir, si exime al trabajador de la obligación de responder, proporcionaría una garantía menor que no impediría que muchas veces los trabajadores se sientan obligados a contestar para preservar su relación laboral ${ }^{43}$.

En realidad, poco importa desde un punto de vista práctico su configuración, pues el establecimiento de un derecho siempre lleva consigo el deber de respetarlo, so pena de dejarlo vacío de contenido ${ }^{44}$. Otra cosa es que se doten o no mecanismos que garanticen su efectividad.

Es más, acogiendo una visión más amplia, debe tenerse en cuenta que la vulneración de estos derechos puede venir provocada por una actuación del empresario, con el que se establece una relación jerárquica o vertical, o por la de otros empleados, incluidos directivos y mandos intermedios.

\footnotetext{
${ }^{41}$ Miñarro Yanini, Margarita. La "Carta de derechos digitales" de los trabajadores ya es ley: menos claros que oscuros en la nueva regulación. Revista de Trabajo y Seguridad Social-CEF, Centro de Estudios Financieros, no 430, 2019, p. 13; Serrano Olivares, Raquel. Los derechos digitales..., ob. cit., p. 226.

${ }^{42}$ Todolí Signes, Adrián. Nuevos derechos digitales..., ob. cit., p. 9/21 con cita de la STC 137/1986, de 6 de noviembre.

${ }^{43}$ Lahera Forteza, Jesús, 2019. ¿Es solo márketing el derecho a desconectar? En: Cinco Días [en línea] Recuperado el 02/03/19 de https://cincodias.elpais.com/cincodias/2019/01/29/companias/1548776510_626973.html

${ }^{44}$ En este sentido se ha manifestado alguna autora, pues entiende que el derecho a la desconexión comprende una "doble faz" que debe desplegar y que incluye tanto un deber de abstención empresarial (derecho a no ser "molestado" o "contactado") como una facultad subjetiva del trabajador (derecho a no responder). Véase: Igartua Miró, María Teresa. El derecho a la desconexión..., ob. cit., p. 66. En el mismo sentido, Molina Navarrete, C. que considera que la desconexión digital requeriría una doble medida: "el poder de autodeterminación del trabajador, plenamente libre para no responder, de un lado, y el deber del empleador de abstenerse de realizar disposición alguna en tal sentido, de otro" [Cfr. Jornada laboral..., ob, cit., p. 270]. El mismo autor, en otra obra afirma que "no hay verdaderos derechos sin obligaciones, sin que derechos ni obligaciones puedan tener una auténtica existencia sin una norma de conducta que así lo reconozca y, además, lo proteja con garantías efectivas" [Cfr. Molina Navarrete, Cristóbal. El tiempo ..., ob. cit., p. 896].
} 
La doctrina que ha estudiado la regulación francesa entiende que el legislador galo intentó abarcar al conjunto de relaciones existentes en la empresa, incluyendo las de carácter horizontal, evitando una "visión simplista, que encierra el derecho a la desconexión en la relación jerárquica patrón/trabajador" ${ }^{45}$. En este sentido, su configuración podría plantearse como una obligación, pero no solo del empresario sino también del trabajador o, al menos, como una corresponsabilidad del trabajador y del empresario ${ }^{46}$, de manera que compromete al trabajador a respetar el tiempo de descanso del resto de miembros de la organización. Por ello, el empresario debería abstenerse de ejercer sus facultades de organización y control fuera de la jornada laboral del trabajador y, además, debería garantizar la efectividad del tiempo de descanso, articulando las medidas necesarias para que toda la plantilla cumpla con su deber de no contactar con otros trabajadores fuera de la jornada.

La corresponsabilidad en la desconexión, fue la opción elegida por el "informe Mettling". Ahora bien, lo que no parece razonable es que la obligación del trabajador sea para consigo mismo, esto es, una "obligación a desconectar" que pudiera abrir la puerta al poder disciplinario en caso contrario. Y es que la ley no tiene un enfoque sancionador para el trabajador sino de establecimiento de garantías.

Pues bien, la literalidad de nuestra norma da a entender que se ha optado por configurar la desconexión digital como un derecho del trabajador y no como un deber empresarial, al menos, de forma expresa. Dicho con otras palabras, tal y como ya hizo la legislación laboral francesa el acento se ha puesto en el trabajador ${ }^{47}$. Esto, además, puede explicar que su reconocimiento legal no vaya acompañado de la previsión de responsabilidades específicas para las empresas incumplidoras.

Ciertamente, el reconocimiento expreso de la obligación empresarial, aunque sea con un alcance simbólico (es decir, sin prever concretas responsabilidades o sanciones), habría contribuido a promover y acentuar el compromiso de la empresa en la materia ${ }^{48}$. Pero lo que no puede afirmarse es que, sin tal reconocimiento, el empresario tenga libertad para no respetar el tiempo de descanso del trabajador o que este último tenga la obligación de continuar trabajando después de su jornada y de responder a los requerimientos de la empresa. En el primer caso, porque la orden empresarial que desconozca el derecho a la desconexión debe ser considerada ilícita, así como también tendrá esta consideración cualquier sanción impuesta al trabajador por no responder a dichos requerimientos o a cualquier otro efectuado por parte de clientes y terceros ${ }^{49}$. Y en el segundo, de forma coherente con lo anterior, porque con el reconocimiento del derecho se proporciona al trabajador un ius resintentiae frente a la orden empresarial, pudiendo evitar el principio de solve et repete que emana de los arts. 5.a, 5.c y 20.1 ET. En nuestra opinión, ya cabía la oposición del trabajador antes de la LOPDP, pues se trata de una orden ajena al marco temporal que limita la relación laboral, lo que ya de por sí la convierte en ilegítima, independientemente de otros considerandos, como el hecho de que pueda

\footnotetext{
${ }^{45}$ Cfr. Cialti, Pierre-Henri. El derecho a la desconexión..., ob. cit., p. 181.

${ }^{46}$ Cita dicho autor una cláusula de convenio colectivo sectorial francés que obliga al trabajador a desconectarse de las herramientas de desconexión remota (ibídem, p. 168).

${ }^{47}$ Mathieu, Chantal, Péretié, Marie-Madeleine y Picault, Alex. Le droit a la déconnexion: une chimere? Revue de droit du travail, n. ${ }^{\circ} 10,2016$, p.592.

${ }^{48}$ Cialti, Pierre-Henri. El derecho a la desconexión..., ob. cit., p. 177. En este sentido, y a raíz de su inclusión en el convenio colectivo del Grupo Axa, la directora de relaciones laborales y diversidad e inclusión de dicha empresa, reconoció el efecto sensibilizador que conlleva pues desde entonces, "los managers mandan menos emails fuera de hora y que saben que el trabajador no tiene la obligación de responder enseguida, sino que el trabajo puede esperar para el día siguiente”. En Palacios, Cristina, 2018. El derecho a la desconexión digital y su aplicación práctica. En: ElDerecho.com. Recuperado el 02/03/19 de https://elderecho.com/el-derechoa-la-desconexion-digital-y-su-aplicacion-practica. Ya el propio reconocimiento legal cumple una función pedagógica o recordatoria [Requena Montes, Óscar. La desconexión digital en España: propuesta de regulación desde la prevención del estrés", en AA.VV. Os impacto das novas tecnologias no direito do trabalho, preprint, p. 37/42].

${ }^{49}$ Pérez de los Coвos, Francisco. Poderes del empresario y derechos digitales del trabajador. Trabajo y derecho: nueva revista de actualidad y relaciones laborales, Wolters Kluwer, no 59, 2019, p. 9/13. Recurso electrónico recuperado el 12/12/19 de la BD Smarteca.
} 
implicar por su acumulación un riesgo para el trabajo o llegar a dañar un derecho constitucional ${ }^{50}$. Ahora, con el reconocimiento legal esta facultad del trabajador se ve reforzada.

En definitiva, se podría reprochar al legislador no haberse esmerado un poco más en la delimitación normativa del derecho, pero "el concepto es por sí mismo suficientemente expresivo como para impedir su lectura minimizadora" ${ }^{51}$. Y, en todo caso, la negociación colectiva puede atemperar esta anómala, aunque habitual, construcción de la desconexión digital haciendo hincapié en el deber empresarial de abstención.

\section{Instrumentalización de la desconexión digital a través de la Negociación colectiva}

\subsection{Consideraciones generales}

Como en el caso francés, que parece ser el espejo en el que se ha mirado el legislador español, la normativa no establece un régimen jurídico expreso sobre el derecho a la desconexión digital, sino que lo reconoce expresamente en el apartado primero y, en el apartado segundo, deja en manos de la autonomía colectiva su desarrollo. Más concretamente, el art. 88.2 LOPDP determina que "las modalidades de ejercicio de este derecho atenderán a la naturaleza y objeto de la relación laboral, potenciarán el derecho a la conciliación de la actividad laboral y la vida personal y familiar y se sujetarán a lo establecido en la negociación colectiva o, en su defecto, a lo acordado entre la empresa y los representantes de los trabajadores".

Esta forma de proceder tiene defensores entre doctrina ${ }^{52}$, pero también detractores que consideran que supone una debilidad legal ${ }^{53}$, al dotarla de carácter meramente programático ${ }^{54}$. En nuestra opinión, el protagonismo dado a la negociación colectiva es positivo, en cuanto que esta fuente normativa permite adaptar y de acercar la regulación a las necesidades sectoriales y empresariales de forma más precisa y está capacitada para hallar un "justo equilibrio" a través de una regulación pactada y consensuada ${ }^{55}$. Aun así, no puede obviarse que la regulación legal ha dejado muchos flecos sueltos y que se podría haber articulado mejor la intervención de la autonomía colectiva a fin de garantizar la presencia del derecho en los procesos de negociación, incluyéndolo como contenido mínimo del convenio colectivo en el art. 85.3 ET ${ }^{56}$; o estableciendo un concreto deber de negociar. Igualmente resulta criticable que no se haya previsto un régimen jurídico legal supletorio que garantice unos mínimos en defecto de pacto colectivo ${ }^{57}$.

\footnotetext{
${ }^{50}$ Comparte esta opinión Taléns Visconti, Eduardo. El derecho a la desconexión digital en el ámbito laboral. Revista Vasca de Gestión de Personas y Organizaciones Públicas, Instituto Vasco de Administración Pública, n. ${ }^{\circ}$ 17, 2019, p. 57.

${ }^{51}$ Cfr. Pérez de los Cobos, Francisco. Poderes del empresario..., ob. cit., p. 9/13.

${ }^{52}$ Entre otros: Ushakova, Tatsiana. De la conciliación a la desconexión tecnológica. Apuntes para el debate. Nueva Revista Española de Derecho del Trabajo, Thomson Reuters-Aranzadi, no 192, 2016, p. 120; Gordo González, Luís. El Derecho del Trabajo 2.0: la necesidad de actualizar el marco de las relaciones laborales a las nuevas tecnologías. Revista de Información Laboral, Lex Nova, no 12, 2017, p. 171. Recurso electrónico recuperado el 02/03/19 de la BD Aranzadi; TaLÉNs VisconTI, Eduardo. La desconexión digital..., ob. cit., p. 9/12.

${ }^{53}$ Alemán Páez, Francisco. El derecho de desconexión digital, ob. cit., p. 15/29. En el mismo sentido, considera que supone un "debilitamiento" González LabradA, Manuel. El derecho a la desconexión digital en el ámbito laboral: naturaleza y alcance. Revista

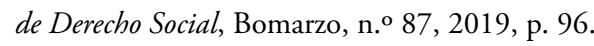

${ }^{54}$ Vallecillo Gámez, María Rosa. El derecho a la desconexión..., ob. cit., p. 175.

${ }^{55}$ Debe repararse en que la digitalización conlleva riesgos para los trabajadores, pero también ventajas para la empresa, de modo que una legislación excesivamente rígida, homogénea y unilateral puede excluir estas últimas. Véase: Molina Navarrete, Cristóbal. Jornada laboral..., ob. cit., pp. 271 y 272.

${ }^{56}$ Tascón López, Rodrigo. El derecho de desconexión..., ob. cit., p. 15/28.

${ }^{57}$ Para la doctrina, si la autonomía colectiva no intervine, podemos encontrarnos ante un derecho vacuo - LAHERA ForTEZA, Jesús, 2019. ¿Es solo márketing..., ob. cit. -, lo que, como se manifiesta en este trabajo, en nuestra interpretación no tiene por qué ser así.
} 
No obstante, a nuestro juicio, cabe esperar que los tribunales eviten que el derecho quede privado de eficacia. Como ya se dijo, el derecho a desconectar ya existía implícitamente en el ordenamiento jurídico que dispensaba mecanismos de protección para el trabajador ante conductas empresariales que invadieran su tiempo de descanso y su vida familiar y personal. A mayor abundamiento, su reconocimiento legal debe entenderse como un refuerzo, una garantía específica para afrontar los cambios introducidos en la organización del trabajo a consecuencia del avance y el desarrollo de la tecnología. Por tanto, solo con su reciente positivización ya se puede entender que estamos ante un "derecho subjetivo perfecto" que el trabajador podrá ejercer incluso en defecto de pacto, oponiéndose a responder sin que por ello pueda ser sancionado. El papel de la negociación colectiva es el de lograr su "plena efectividad" ${ }^{58}$. Al convenio le corresponde su desarrollo, no su reconocimiento, ya que esta función es desempeńada por la ley ${ }^{59}$, por lo que hay que evitar la incorporación de meras declaraciones de intenciones. Podría argumentarse en contra que si no se regulan medidas concretas difícilmente quedará garantizado, pero hay que tener en cuenta que, en todo caso, el empresario deberá definir las modalidades de su ejercicio en la política interna, por lo que está obligado a llevar a cabo ciertas acciones a fin de garantizar el respeto al tiempo de no trabajo de sus empleados tal y como ordena el art. 88.1 LOPDP. Y estas medidas, concretadas en el protocolo empresarial al que luego nos referiremos, no pueden hacer una interpretación inadecuada o abusiva del derecho a la desconexión en la medida en que serán susceptibles de un ulterior control judicial.

\subsection{El contenido de la regulación: la modelación y modulación del derecho}

El principal cometido que tiene la negociación colectiva es definir las modalidades de ejercicio del derecho, atendiendo a la naturaleza y objeto de la relación laboral y potenciando el derecho a la conciliación de la vida laboral, personal y familiar. En este sentido, conviene aclarar qué debe entenderse por modalidades de ejercicio y cómo opera la referencia a la naturaleza y objeto de la relación laboral.

Pues bien, el art. 88 LOPDP con esta expresión se está refiriendo a la implementación de medidas concretas para garantizar el derecho ${ }^{60}$, es decir, a las acciones, herramientas, técnicas o sistemas que se pretende emplear. El legislador ha optado por no pre-definir las posibles acciones, ni siquiera ha previsto un régimen supletorio o un listado ejemplificativo de medidas. Por tanto, se apela a la innovación y creatividad de los sujetos negociadores para establecer las más apropiadas para cada caso. Evidentemente, las experiencias ya puestas en práctica pueden servir como modelo para garantizar el derecho a la desconexión digital ${ }^{61}$. Consideramos que incluso el convenio podría articular un régimen disciplinario para aquellos empleados que con su actuación obstaculicen el pleno disfrute del descanso de otros trabajadores de la empresa (no así cuando se produzca un autoincumplimiento del derecho). De esta manera, la norma permite todo tipo de medidas, sin imponer fórmulas concretas para alcanzarlo y sin que pueda deducirse una preferencia legal por el uso de sistemas tecnológicos que bloqueen de forma automática las comunicaciones fuera del horario de trabajo. Aun así esta opción será la más sencilla y eficaz para garantizar el descanso y la desconexión

\footnotetext{
${ }^{58}$ Igartua Miró, María Teresa. El derecho a la desconexión..., ob. cit., p. 76.

${ }^{59}$ Pérez de los Cobos, Francisco. Poderes del empresario..., ob. cit., p. 9/13. En contra, Molina Navarrete, C. considera, al hilo de la regulación francesa, que es un "derecho condicionado" a su regulación colectiva [Cfr. Jornada laboral..., ob. cit., 272].

${ }^{60}$ Requena Montes, Óscar. La desconexión digital..., ob. cit., p. 28/43.

${ }^{61}$ En este sentido, pueden ir desde el bloqueo automático de las comunicaciones, la recepción diferida de correos, la redirección del flujo de mensajes y llamadas, acciones de concienciación, etc. Con mayor detalle, véase: Ciatti, Pierre-Henri. El derecho a la desconexión..., ob. cit., p. 178; y Barrios Baudor, Guillermo Leandro. El derecho a la desconexión..., ob. cit., p. 12.
} 
digital $^{62}$. De hecho, si realizamos una lectura del precepto en clave de prevención de riesgos laborales, la opción por estos sistemas automáticos de bloqueo u otras medidas similares resulta más recomendable -como luego analizamos-, siempre que resulte razonable y no perjudique el normal desarrollo de la actividad de la empresa.

Los autores que han estudiado la materia han entendido que de la dicción del precepto se desprende que el legislador está admitiendo ciertas graduaciones en relación "la naturaleza y objeto de la relación laboral ". Por un lado, esto puede calificarse como una falta de compromiso del legislador $^{63}$ o una devaluación del derecho ${ }^{64}$, pues permitiría limitar o restringir el disfrute del derecho a algunos trabajadores concretos. Sin embargo, por otro lado, no puede obviarse que ciertas realidades laborales que tienen una configuración diversa en cuanto al tiempo de trabajo deberán tomarse en consideración para establecer una regulación equitativa ${ }^{65}$. Es este el sentido que hay que dar a la previsión normativa, pues hay colectivos profesionales en los que no es posible establecer una desconexión rígida y total, ya que la propia naturaleza de su prestación de servicios puede requerir que sean contactados fuera de su tiempo de trabajo. Se trata de supuestos ya conocidos, como aquellos que tienen un tiempo en régimen de localización o el de permanencia a disposición del empresario sin presencia o fuera del centro de trabajo, cuya realización, como ha confirmado la SAN (Social) de 20 de septiembre de 2018, Rec. 125/2018, no implica la realización de trabajo efectivo si no llega a concretarse la intervención del trabajador.

Especial atención merece también su aplicación a los supuestos de trabajadores a tiempo parcial en relación con la realización de las horas complementarias y las de realización voluntaria, por cuanto que la normativa legal no establece previsión alguna en cuanto a la forma y momento de su convocatoria. $\mathrm{O}$, en el mismo sentido, la posibilidad de realizar horas extraordinarias por fuerza mayor para "prevenir o reparar siniestros y otros daños extraordinarios y urgentes" ex art. 35.3 ET, que puede requerir el mantenimiento de algún cauce excepcional de contacto con el trabajador, pese a que este ejercite su derecho a desconexión. Muchos convenios han hecho uso de esta última posibilidad para exceptuar su ejercicio, pero no han concretado nada al respecto de la forma, momento y canales para el llamamiento, lo que puede situar al trabajador en un estado de permanente alerta y conexión.

La doctrina también apunta otras fórmulas de modulación del derecho en atención al diverso cómputo del trabajo efectivo en aquellos trabajos en los que la separación de la vida profesional y personal se encuentra desdibujada, como en los casos del trabajo a distancia o en aquellos trabajos en los que suele primar la flexibilidad horaria, lo que conlleva mayor capacidad de auto-organización junto con una mayor deuda de disponibilidad hacia la empresa. Especial atención requerirán los supuestos de teletrabajo, ya sea de forma completa u ocasional (también denominado smartworking).

El teletrabajo, se configura como un supuesto de trabajo a distancia regulado en el art. $13 \mathrm{ET}^{66}$, ha ido cobrando importancia al compás de la revolución digital y ha adquirido una nueva dimensión a raíz de la crisis sanitaria provocada por la COVID-19. Las autoridades han impulsado el teletrabajo como una fórmula de distanciamiento social a fin de evitar el contagio y frenar la epidemia. El

${ }^{62}$ En este sentido, también Fernández Avilés, José Antonio. Cronorreflexión..., ob. cit., p. 14; TAscón López, Rodrigo. El derecho de desconexión..., ob. cit., p. 10/28.

${ }^{63}$ Igartua Miró, María Teresa. El derecho a la desconexión..., ob. cit., p. 67.

${ }^{64}$ Alemán PÁez, Francisco. El derecho de desconexión digital, ob. cit., p. 15/29.

${ }^{65}$ Véase: Tascón López, Rodrigo. El derecho de desconexión..., ob. cit., p. 11/28.

${ }^{66}$ Expresión que sustituye a la de trabajo a domicilio que figuraba en anteriores versiones de la normativa laboral y que pretendía dar cobertura a la realidad del trabajo industrial a domicilio desempeñado mayoritariamente por mujeres y que, en muchas ocasiones, se realizaba en la economía sumergida. Véase: García Ramon, María Dolors; Baylina Ferré, Mireia; Cruz Villalón, Josefina; y otras. El trabajo industrial en la España rural: un análisis desde la perspectiva de género. Boletín de Estudios Geográficos, Universidad Nacional de Cuyo: Instituto de Geografía, no 92, 1996, pp. 217-246. 
Real Decreto-ley 8/2020, de 17 de marzo, de medidas urgentes extraordinarias para hacer frente al impacto económico y social del COVID-19 en su art. 5 establece el carácter preferente del trabajo a distancia y conmina a las empresas a establecer "sistemas de organización que permitan mantener la actividad por mecanismos alternativos, particularmente por medio del trabajo a distancia". En esta tesitura las empresas que incluían en su estructura organizativa el teletrabajo han podido afrontar mejor esta crisis que las que no lo hacían. Otras muchos han comenzado a incorporar esta modalidad contractual con tal de frenar el descenso de actividad que aparejan las medidas de contención adoptadas en el Real Decreto 463/2020, de 14 de marzo, por el que se declara el estado de alarma para la gestión de la situación de crisis sanitaria ocasionada por el COVID-19. Con seguridad esta crisis traerá consigo un cambio de paradigma aumentando el número de puestos de teletrabajo en las empresas.

Pero el mayor recurso al teletrabajo no es posible solamente desde el inicio de la crisis sanitaria. Cabe recordar que el Real Decreto-ley 6/2019, de 1 de marzo, de medidas urgentes para la garantía de la igualdad de trato y de oportunidades entre mujeres y hombres en el empleo y en la ocupación ${ }^{67}$, que supuso la revisión de diversas instituciones laborales, entre ellas el derecho a adaptación de la jornada, modificó el artículo 34.8 ET estableciendo que "las personas trabajadoras tienen derecho a solicitar las adaptaciones de la duración y distribución de la jornada, en la ordenación de tiempo de trabajo y de prestación, incluida la prestación de su trabajo a distancia [el subrayado es nuestro], para hacer efectivo su derecho a la conciliación de la vida laboral y familiar. Dichas adaptaciones deberán ser razonables y proporcionadas en relación con las necesidades de la persona trabajadora y con las necesidades organizativas o productivas de la empresa". Como no podría ser de otra manera, la norma prevé que "en la negociación colectiva se pactarán los términos de su ejercicio". Dicho con otras palabras, al amparo del derecho de la adaptación de la jornada se reconoce a los trabajadores y trabajadoras el derecho a solicitar la modalidad del trabajo a distancia, lo cual supone, a nuestro juicio, una matización del tradicional carácter voluntario que tenía este para las partes (STS de 11 de abril de 2005, Rec. 143/2004), al menos, en lo que respecta a la voluntariedad para la empresa. Además, porque aun en defecto de previsión convencional, las posibilidades de ser rechazado por la empresa cuando se solicite para hacer efectivo el derecho a la conciliación son más limitadas con respecto al estado normativo anterior ${ }^{68}$.

El mayor volumen de teletrabajadores que ha habido en los últimos tiempos contrasta con las carencias de regulación y la falta de una normativa homogénea y clara. En efecto, la norma central y de referencia -el artículo 13 ET-adolece de una falta de especificidad por cuanto que regula en general el trabajo a distancia, no siendo un componente esencial de todo el trabajo a distancia el empleo de las NTICs como sí lo es en cambio para el teletrabajo ${ }^{69}$. Por su parte, en el sector público sí que se han aprobado varias disposiciones normativas tanto en el seno de la Administración Central del Estado, como por parte de las Comunidades Autónomas pero que, a parte de tener un contenido y alcance diverso en cada una de ellas, solo resultan aplicables a empleados públicos. Por tanto, es la negociación colectiva el instrumento normativo más recurrente para su desarrollo, así como el más idóneo habida cuenta de su capacidad de adaptación ${ }^{70}$. Idea que también se desprende del Acuerdo Marco Europeo sobre el Teletrabajo (AMET) promovido por el Consejo Europeo y firma-

\footnotetext{
${ }^{67}$ BOE n. ${ }^{\circ} 57$ de 08-03-19.

${ }^{68}$ Indica el tercer párrafo del art. 34.8 ET que, en ausencia de previsión por el convenio, el trabajador igualmente podrá solicitar la adaptación de su jornada o el recurso al teletrabajo y la empresa deberá abrir un periodo de negociación individual de un máximo de 30 días con el trabajador que deberá finalizar: 1) con aceptación de la solicitud; 2) con una propuesta alternativa que le permita la conciliación laboral y familiar; o, 3) con una negativa motivada basándose en razones objetivas.

${ }^{69} \mathrm{Y}$ ello, a pesar de su carácter relativamente reciente, ya que fue modificado por el Real Decreto ley 3/2012, de 10 de febrero, de medidas urgentes para la reforma del mercado laboral (BOE n.o 36 de 11-02-12).

${ }^{70}$ Navarro Quintanilla, Raquel Yolanda. El teletrabajo: de la dispersión normativa presente a la necesaria regulación normativa europea y estatal futura, En AA.VV. El futuro del trabajo que queremos, Vol. II, Madrid, Ministerio de Empleo y Seguridad Social, 2017, pp. 107-122. Recurso electrónico recuperado el 02/03/17 de https:/www.ilo.org/wcmsp5/groups/public/---europe/---rogeneva/---ilo-madrid/documents/publication/wcms_615487.pdf
} 
do por los interlocutores sociales europeos en 2002 con la finalidad de que los trabajadores puedan "reconciliar vida profesional y vida social y darles una mayor autonomía en la realización de sus tareas". No obstante, el AMET adolece de carácter vinculante, pues se limita a dar una definición de teletrabajo ${ }^{71}$, establecer una serie de principios básicos e interpelar a los actores sociales nacionales para que los incorporen en la negociación colectiva nacional. Tal labor, fue llevada a cabo mediante el Acuerdo Interconfederal para la Negociación Colectiva ${ }^{72}$ que se planteaba promover la adaptación y el desarrollo de su contenido a la realidad española, teniendo especialmente en cuenta aquellos ámbitos en los que puede existir más interés, de manera que se impulse una mayor y adecuada utilización del teletrabajo, favorable tanto a las empresas como a los trabajadores. El contenido del AMET se ha ido incluyendo en los sucesivos acuerdos marco interprofesionales sin apenas variaciones, nuevas intervenciones o adaptaciones al contexto actual, más allá de recordar el carácter voluntario y reversible del teletrabajo, la igualdad de derechos respecto a los trabajadores presenciales de la empresa o la conveniencia de que se regulen aspectos como la privacidad, la confidencialidad, la prevención de riesgos, las instalaciones o la formación. Eso sí, remitiendo siempre al propio contenido del AMET. ${ }^{73}$

Pero lo cierto es que el alcance de la implementación que ha tenido en la negociación colectiva sectorial ha sido escaso, ya que muchos convenios se han limitado a reproducir el AMET en sus propios términos, sin desarrollar aquellos aspectos a los que el mismo se refiere o han desarrollando solo algunas de sus materias de forma parcial ${ }^{74}$. Por no hablar de cómo son ignoradas entre sí las diferentes regulaciones de desconexión digital y teletrabajo incorporadas a los más recientes pactos negociales $^{75}$, cuando en realidad son aspectos estrechamente conectados, en la medida en que ambos versan sobre materias relacionadas con el tiempo de trabajo y de no trabajo, donde la negociación colectiva cuenta con un amplio margen de actuación.

En fin, la modalidad del teletrabajo ofrece múltiples ventajas a las empresas (aumento de la productividad, ahorro de costes de empresa, reducción de la tasa de absentismo, flexibilidad), y a los trabajadores, en cuanto que les permite adaptar su jornada a sus necesidades incrementando las posibilidades de conciliar vida laboral y personal y familiar, pero indudablemente también trae consigo desventajas. En el teletrabajo se desdibujan los límites tanto espaciales como temporales que separan la vida laboral de la vida privada. La desaparición de las fronteras espaciales y temporales entre las esferas laboral y privada puede generar a la vez una clara interferencia entre el trabajo y el hogar, pudiéndose llegar a producir una situación de estrés y de dificultad para conciliar, a la práctica, la vida laboral y familiar. El Informe conjunto que presentó la OIT y Eurofund en $2019^{76}$ demuestra que los estos trabajadores trabajan más horas que los que llevan a cabo la prestación de servicios en las dependencias empresariales ocupando tiempos propios del descanso (trabajo vespertino y fines de semana) y sin una retribución adicional. La manera de combatir estos efectos negativos se

\footnotetext{
71 "El teletrabajo es una forma de organización y/o de realización del trabajo, utilizando las tecnologias de la información en el marco de un contrato o de una relación de trabajo, en la cual un trabajo que podría ser realizado igualmente en los locales de la empresa se efectúa fuera de estos locales de forma regular".

${ }^{72}$ Resolución de 31 de enero de 2003, de la Dirección General de Trabajo, por la que se dispone la inscripción en el Registro y publicación del Acuerdo Interconfederal para la Negociación Colectiva 2003-ANC 2003 (BOE n. 47 de 24 de febrero de 2003).

${ }^{73}$ El último, el IV Acuerdo para el Empleo y la Negociación Colectiva (Resolución de 17 de julio de 2018, de la Dirección General de Trabajo; BOE n. ${ }^{\circ} 173$ de 18-07-18), que no prevé nada expresamente al respecto si bien prorroga en sus propios términos a su predecesor, el III Acuerdo para el Empleo y la Negociación Colectiva 2015, 2016 y 2017 (Resolución de 15 de junio de 2015, de la Dirección General de Empleo; BOE n. 147 de 20-06-15), que se pronuncia en el alcance expresado y con remisión al AMET.

${ }^{74}$ Véanse todos los citados en Navarro Quintanilla, Raquel Yolanda. El teletrabajo..., ob. cit., pp. 118-119.

${ }^{75}$ Un ejemplo bastante gráfico, el del Convenio Colectivo Estatal de Perfumerías y afines (Resolución de 8 de agosto de 2019; BOE n. ${ }^{\circ} 199$ de 20 de agosto de 2019), en el que contempla el régimen del teletrabajo que se regula en el art. 15 y, acto seguido, en el art. 16 se regula el derecho a la desconexión.

${ }^{76}$ OIT-Eurofund, Trabajar en cualquier momento y en cualquier lugar: consecuencias en el ámbito laboral, Ginebra: OIT, 2019. Recuperado de https://www.ilo.org/wcmsp5/groups/public/---ed_protect/---protrav/---travail/documents/publication/wcms_712531.pdf
} 
ha de mover en dos frentes, mediante un adecuado control y registro de la jornada y mediante la implementación de medidas de prevención de riesgos laborales y de desconexión digital, con el fin de evitar la sobrecarga de trabajo y el estrés que conlleva.

En este sentido, abordar el derecho a la desconexión se reputa esencial para los teletrabajadores, especialmente, para aquellos casos en que se requiera una modulación del mismo. Como recuerda la STSJ Cataluña de 15 de enero de 2019, rec. 5609/18, la realidad del teletrabajo es muy diversa y no en todas las modalidades se cuenta con el mismo sistema de cómputo del tiempo de trabajo, pudiendo pactarse supuestos de total libertad horaria (centrado esencialmente en la consecución de objetivos) o quedando el trabajador sujeto a un horario delimitado y cerrado que debe cumplir. Entre ambos, un término mixto, en el que se deben cumplir ciertas tareas o con ciertos tiempos de disponibilidad durante un horario delimitado, siendo el resto de la jornada auto-gestionada por el empleado ${ }^{77}$. Ello requiere el establecimiento de medidas de desconexión adaptadas a cada situación y si se debe pactar un régimen matizado y flexible de la desconexión para permitir el desarrollo del teletrabajo en los términos pactados es la autonomía de la voluntad colectiva quien debe realizar dicha tarea.

Ahora bien, en defecto de esta, quizás sería más necesario que en otros supuestos que se recoja en el acuerdo individual de teletrabajo ex art. 13.2 $\mathrm{ET}^{78}$, cuestión que no interesa solo al trabajador sino también a la empresa. No resulta ocioso traer a colación la STSJ Castilla y León (Valladolid) de 3 de febrero de 2016, rec. 2229/15, que condena a la empresa al pago de horas extraordinarias por no haber ejercido ningún tipo de control sobre la jornada del teletrabajador. Aunque la empresa alegó que el control y registro de la jornada no se llevó a cabo para no invadir el derecho a la intimidad e inviolabilidad del domicilio, el tribunal rechazó el argumento recordándole que el control del tiempo de trabajo es su responsabilidad -también respecto al teletrabajo- y que la finalidad de los límites de la jornada y descansos es garantizar la protección de la salud, de la cual es deudora en aquellos aspectos que conectan con la relación laboral. La empresa debería haber establecido normas sobre tiempo de trabajo e instrumentos de declaración y control, siendo el trabajador a quien correspondía rechazarlos si consideraba vulnerados sus derechos fundamentales, ya que "en el caso del trabajo desarrollado con conexión a internet el control del ejercicio laboral a distancia, mediante la comprobación de la conexión del trabajador a la intranet empresarial y de su actividad en la red, no supone en principio y en condiciones normales invasión del espacio protegido bajo el concepto de domicilio y además es susceptible de inspección y control por la Administración Laboral'. La omisión de control empresarial -aun flexiblesy la ausencia de pautas claras sobre tiempo de trabajo respetuoso con el descanso laboral es "equivalente a crear un espacio de total impunidad y alegalidad en el trabajo a distancia y en el domicilio".

A nuestro juicio, para concluir, la modulación del disfrute de la desconexión digital con base en la referencia a la naturaleza y objeto de la relación laboral no abre tantas posibilidades como en un principio pudiera parecer. Es cierto que juega como una habilitación para restringir el disfrute del derecho, pero también como un límite para no extrapolar este régimen de excepción a cualquier relación laboral, pues únicamente cuando exista una justificación objetiva basada en las especiales características del puesto de trabajo podrá llevarse a cabo por la negociación colectiva. Precisamente, si la ley remite a la autonomía de la voluntad colectiva para su regulación es por su capacidad negociadora, de modo que la eventual limitación del derecho a la desconexión debe tener un carácter transaccional en la que se pacte una contraprestación específica o el establecimiento de sistemas de cómputo de tiempo de trabajo que permitan incluir el tiempo de conexión digital extra como tiempo de trabajo efectivo ${ }^{79}$.

\footnotetext{
${ }^{77}$ Por cierto, que la citada sentencia versa sobre un supuesto de despido por transgresión de la buena fe contractual en el que la trabajadora incumple el horario de teletrabajo.

${ }^{78}$ Más reticente a esta posibilidad se posiciona Igartua Miró, María Teresa. El derecho a la desconexión..., ob. cit., p. 68.

${ }^{79}$ Sobre esto último: Pérez de los Cobos, Francisco. Poderes del empresario..., ob. cit., p. 10/13.
} 


\subsection{El alcance y significado del art. 91 LOPDP en relación a la desconexión digital}

Finalmente, el art. 91 LOPDP hace un llamamiento genérico a la negociación colectiva como instrumento de refuerzo para que se establezcan "garantías adicionales de los derechos y libertades relacionados con el tratamiento de los datos personales de los trabajadores y la salvaguarda de derechos digitales en el ámbito laboral'. Dicho llamamiento se realiza conjuntamente para la regulación de los derechos digitales laborales previstos en los artículos 87 y ss. Algún autor ha afirmado que, en términos generales, el legislador ha configurado estos derechos como una "suerte de presunción de intromisión legitima del empleador en la confidencialidad de los datos y en la esfera privada de los trabajadores" por lo que, necesariamente, el papel de los convenios debe orientarse a revertir este enfoque, reforzando las escasas garantías laborales que se prevén y estableciendo límites a las amplias facultades de control empresarial ${ }^{80}$. Pero el art. 91 resulta redundante para el caso de la desconexión digital que no cuenta con un régimen jurídico-positivo legal que pueda mejorarse colectivamente.

Ahora bien, cabría dilucidar si la negociación colectiva también puede abordar la regulación de las cuestiones a las que alude el art. 88.3 LOPDP cuando establece el contenido de la política empresarial: acciones de formación y sensibilización orientadas a la prevención del riesgo de fatiga informática. En Francia, donde se daba una situación similar, la doctrina concluyó, entendemos que con acierto, que estos contenidos podían ser objeto de regulación colectiva ${ }^{81}$, puesto que la distribución material realizada en los apartados $2^{\circ}$ y $3^{\circ}$ del art. 88 obedece al diferente enfoque de las distintas dimensiones del derecho a la desconexión, derivando los aspectos relacionados con la seguridad y salud laboral al empresario, en relación con la deuda de protección que le atribuye el art. 14 LPRL; y los relacionados con las instituciones ordenadoras del tiempo de trabajo y de descanso y con la conciliación de la vida laboral y personal, dónde la negociación colectiva encuentra un amplio margen de actuación. En este sentido, podría entenderse útil el art. 91 LOPDP por cuanto que se están estableciendo garantías adicionales a aquellas que la ley le está encomendando.

\section{El protocolo empresarial de desconexión digital}

A nuestro juicio, los apartados 2 y 3 del art. 88 LOPDP prevén normas que obedecen a una finalidad diversa, pero complementaria y sujetas a límites también diversos, de manera que, mientras que la primera norma pretende garantizar el disfrute del tiempo de descanso y la conciliación conectando con este bloque de instituciones normativas, la segunda se orienta hacia la tutela del derecho a la seguridad y salud de los trabajadores conectando su regulación con el bloque normativo de la prevención de riesgos laborales. Vamos a ocuparnos ahora de esta última.

\subsection{Alcance del deber empresarial de elaborar una politica interna de desconexión}

$\mathrm{El}$ art. 88.3 LOPDP prevé que "el empleador, previa audiencia de los representantes de los trabajadores, elaborará una política interna dirigida a los trabajadores, incluidos los que ocupan puestos directivos, en la que definirán las modalidades de ejercicio del derecho a la desconexión y las acciones de formación y de sensibilización del personal sobre un uso razonable de las herramientas tecnológicas que evite el riesgo de fatiga informática. En particular, se preservará el derecho a la desconexión digital en los supuestos de

\footnotetext{
${ }^{80}$ Cfr. Baylos Grau, Antonio. Los derechos digitales..., ob. cit., p. 2/5 y 3/5.

${ }^{81}$ Cialti, Pierre-Henri. El derecho a la desconexión..., ob. cit., p. 178.
} 
realización total o parcial del trabajo a distancia, así como en el domicilio del empleado vinculado al uso con fines laborales de herramientas tecnológicas".

Esta obligación para el empresario es la mayor aportación del régimen jurídico legal de la desconexión ${ }^{82}$. Con todo, el hecho de que se realicen llamadas a la negociación colectiva y a la regulación unilateral por parte de la empresa en compartimentos estancos puede suscitar algunos problemas en torno a su coordinación. A diferencia de como se ha establecido en el Código de Trabajo francés, en el que el empresario sólo debe elaborar una política de actuación "a falta de acuerdo" en la negociación colectiva, en el caso español, quizás por falta de confianza en la actuación colectiva, se dispone que dicha política debe implementarse en todo caso ${ }^{83}$.

En esta tesitura, si se aborda la regulación de la desconexión digital por la negociación colectiva, el mencionado protocolo no podrá desvirtuar el pacto alcanzado y deberá seguir sus postulados ${ }^{84}$. Ahora bien, en ausencia de dicho pacto, pudiera parecer que se dota a la empresa con "un rol preponderante", otorgándole un poder ilimitado para decidir cuantos aspectos estén relacionados con la desconexión, lo que "dilata excesivamente los márgenes de maniobra del empleador laboral" al establecer una política de carácter programático y con escasa participación por parte los trabajadores ${ }^{85}$.

Sin embargo, si partimos de la premisa de que la hiperconectividad digital es un importante factor de riesgo psicosocial causante de estrés y otros riesgos laborales ${ }^{86}$ y que hay una conexión directa con la seguridad y salud de los trabajadores, la interpretación del art. 88.3 LOPDP debe realizarse a la luz de los mandatos de la LPRL ${ }^{87}$ y su normativa de desarrollo, pues estamos ante una verdadera norma de carácter preventivo extra-sistemática, ubicada fuera de su cuerpo normativo natural.

\subsection{La politica interna como deber especifico de prevención de riesgos laborales}

Ya hemos señalado en este estudio que las NTICs dificultan la desconexión de las obligaciones laborales y son una fuente de generación de riesgos psicosociales, llegando, en casos extremos, a producir "tecno-estrés" ${ }^{8}$. Ello conlleva adoptar un enfoque preventivo del problema, razón por la cual también se había visto con buenos ojos una eventual modificación de la LPRL para que incluyera esta materia ${ }^{89}$.

Lo cierto es que la LOPDP no ha hecho ningún movimiento en este sentido, aunque, al igual que ocurre con las instituciones jurídico-laborales que garantizan el tiempo de descanso, un sector de la doctrina ha defendido que la protección preventiva frente a estos riesgos ya estaría dispensada por las genéricas previsiones de la LPRL con anterioridad a la positivización de la desconexión digital $^{90}$. Así, y en la medida en que la no desconexión puede suponer un riesgo psicosocial para la salud del trabajador, quedaría subsumido dentro del concepto de riesgo laboral frente al que opera la deuda empresarial de protección prevista en el art. 14 LPRL. Ello, obligaría al empresario a adoptar una actitud diligente con el fin de evitar los riesgos, evaluar aquellos que no se puedan evitar y

\footnotetext{
${ }^{82}$ Blázquez Agudo, Eva María. Novedades laborales..., ob. cit., p. 12/19.

${ }^{83}$ Igartua Miró, María Teresa. El derecho a la desconexión..., ob. cit., p. 83.

${ }^{84}$ Serrano Olivares, Raquel. Los derechos digitales..., ob. cit., p. 228.

${ }^{85}$ Cfr. Alemán PÁez, Francisco. El derecho de desconexión digital, ob. cit., pp. 17 y 18/29. En este sentido también Igartua Miró, María Teresa. El derecho a la desconexión..., ob. cit., p. 73.

${ }^{86}$ Requena Montes, Óscar. La desconexión digital..., ob. cit., p. 36/42.

${ }^{87}$ En este sentido también Miñarro Yanini, Margarita. La “Carta de derechos...”, ob. cit., p. 13.

${ }^{88}$ Cabe remitir al completo estudio realizado por González Cobaleda, Estefanía. Riesgos psicosociales, derechos fundamentales y NTIC: una perspectiva de protección diferente. Revista de Trabajo y Seguridad Social-CEF, Centro de Estudios Financieros, no 387, 2015, pp. 29 y ss.

${ }^{89}$ TALÉNS Visconti, Eduardo. La desconexión digital..., ob. cit., p. 6/12.

${ }^{90}$ Molina Navarrete, Cristóbal. Jornada laboral..., ob. cit., pp. 276.
} 
combatirlos (art. 15.1.a, b, c y 16 LPRL) ${ }^{91}$. De este modo, estas previsiones deberían bastar para impedir el abuso de los dispositivos electrónicos que puedan menoscabar la salud del trabajador.

También en este sentido se manifestó la doctrina respecto a la regulación francesa al entender que la obligación empresarial de velar por la seguridad y salud se ve reforzada tras la proclamación del derecho a pesar de no incluir medidas específicas. Sin embargo, bien es sabido que, a diferencia de lo que ocurre con otro tipo de riesgos laborales (exposición a agentes químicos, biológicos, ruidos, etc.), la prevención de los riesgos psicosociales no cuenta con un desarrollo normativo específico, lo que dificulta -tal y como ponen de manifiesto diversos informes nacionales e internacionalessu puesta en práctica y la capacidad sancionadora de la Inspección de Trabajo ${ }^{92}$.

Pues bien, el deber de adoptar el protocolo empresarial de desconexión digital, con el contenido que establece la LOPDP, es una medida clara y concreta que la empresa debe observar para tutelar los riesgos psicosociales y que debería incluirse el plan de prevención de riesgos de la empre$\mathrm{sa}^{93}$. En otras palabras, el derecho a la desconexión obliga a una relectura del marco normativo sobre prevención de riesgos laborales que puede reforzar algunas obligaciones que tenían escasa virtualidad en la gestión de los riesgos psicosociales por su falta de desarrollo reglamentario, al contar con una concreta obligación empresarial de carácter legal. Esta relectura impregnaría el contenido de la política de empresa establecido por el art. 88.3 LOPDP.

\subsection{Contenido material del protocolo interno}

A la empresa le compete elaborar una política interna que trate básicamente dos aspectos: la definición de las modalidades de ejercicio del derecho y el diseño de las acciones formativas y de sensibilización sobre el uso de la tecnología desde una perspectiva preventiva. Además, debe incluir y tratar el ejercicio del mismo por dos colectivos que requieren un tratamiento específico: directivos y teletrabajadores. Todo ello, oídos previamente los representantes de los trabajadores. Pero vayamos por partes.

Al igual que la negociación colectiva, a la empresa también le corresponde mediante el protocolo empresarial definir las modalidades de ejercicio del derecho. En este sentido, una primera lectura del apartado tercero del precepto legal puede dar a entender que se deja en manos del empleador el dotar de una regulación adecuada al derecho, o bien permite vaciarlo de contenido, estableciendo una mera declaración formal sin mayor repercusión que la de cumplir el trámite ante una eventual inspección labora ${ }^{94}$, pues aparentemente la ley es poco exigente y pone escasos límites al empleador en la configuración unilateral del disfrute del derecho ${ }^{95}$.

Sin embargo, si se realiza una interpretación sistemática y teleológica de la norma puede alcanzarse una conclusión diversa. Y es que no parece que la ley permita que el protocolo empresarial pueda modular o exceptuar su disfrute para ciertas prestaciones de servicio, circunstancia que sí puede llevarse a cabo a través de la negociación colectiva. El art. 88.2 LOPDPD establece que las modalidades de ejercicio diseñadas por la negociación colectiva "atenderán a la naturaleza y objeto de la relación laboral', sin embargo, tal referencia no se encuentra en el apartado tercero, por lo que el

\footnotetext{
${ }^{91}$ La obligación de evaluación de los riesgos también obliga los de tipo psicosocial (STS 16-2-16, Rec. 250/2014).

${ }^{92}$ Véanse los citados en: Payá Castiblanque, Raúl y Yagüe Blanco, Sergio. Doble discriminación indirecta hacia las mujeres trabajadoras en el sistema de prevención y protección social ante los riesgos laborales nuevos y emergentes de origen psicosocial, En: López Aniorte, María Carmen y Rubio Fernández, Eva María (dir.), Visiones multidisciplinares de la igualdad entre hombres y mujeres, Murcia, Laborum, 2019, pp. 243 y ss.

${ }^{93}$ En este sentido, Cialti, Pierre-Henri. El derecho a la desconexión..., ob. cit., p. 178.

${ }^{94}$ Zamora, Santiago, 2019. Desconexión digital..., ob. cit.

${ }^{95}$ Igartua Miró, María Teresa. El derecho a la desconexión..., ob. cit., p. 83.
} 
protocolo no podrá realizar tal modulación ${ }^{96}$. Tiene sentido que así sea. Cuando nos referíamos a las distintas prestaciones de servicios que pueden requerir una modulación, se vió que esta dimensión de la desconexión se vincula con las instituciones normativas ordenadoras del tiempo de trabajo, materia sobre la que la negociación colectiva posee un amplio margen de intervención. Y lo mismo cabe decir respecto a la conciliación de la vida laboral y privada, además, porque para su refuerzo el convenio podría facilitar el acceso del trabajador a modalidades flexibles de trabajo, estableciendo fórmulas alternativas de disfrute del tiempo de descanso y, por tanto, del derecho a la desconexión.

Este rol se atribuye a la autonomía colectiva y no resulta razonable que se desempeñe igualmente mediante una decisión de carácter unilateral del empresario, por lo que la modulación del disfrute del derecho no podrá articularse a través de un protocolo empresarial. El papel del convenio resulta reforzado, el interés de ambas partes en acordar un regulación suficientemente flexible y equilibrada incentivará a iniciar la negociación y, en esta labor, los negociadores tendrán un amplio margen para lograr la efectividad del derecho que no debe desaprovecharse. Por su parte, la política interna deberá acatar e implementar lo establecido en la negociación colectiva respecto a las modalidades de ejercicio del derecho. Ahora bien, en el caso de que no se produzca este proceso de negociación, el empresario podría intentar, en la medida de lo posible, implementar ciertas medidas mediante pacto individual, pues la LOPDP no lo contempla expresamente pero tampoco lo prohíbe. Eso sí, esta posibilidad solo tendría cabida en defecto de la colectiva ${ }^{97}$.

En consecuencia, mediante el protocolo interno no se podrá establecer un disfrute flexible y adaptado del derecho. No es una fuente normativa válida en tanto en cuanto no es negociada. En cambio, sí que es un instrumento válido para integrar la gestión de los riesgos psicosociales en el plan de prevención de la empresa, en especial el riesgo de fatiga informática. Este entendimiento de la norma en clave preventiva introduce límites importantes al evitar que la regulación unilateral del empresario sea tan laxa que impida la desconexión. Al contrario, en el diseño de las acciones en materia de desconexión, deberá partirse de la necesidad de garantizar una protección eficaz frente a los riesgos laborales, para cuyo cumplimiento deberá adoptar "cuantas medidas sean necesarias" para la prevención de los riesgos profesionales y la eliminación o disminución de los mismos (arts. 2, 14.1 y 2 LPRL). Es decir, deberá adoptar todos los medios necesarios para evitar o reducir los riesgos psicosociales que puede desencadenar la hiperconectividad.

Entendido el protocolo de desconexión como una medida que se integra en el plan de prevención de riesgos laborales de la empresa deberán llevarse a cabo sus dos componentes esenciales: la evaluación de riesgos y la planificación de la actividad preventiva (art. 16.2 LPRL). No cabe, por tanto, establecer unas modalidades de ejercicio del derecho a la desconexión sin llevar a cabo estos dos procesos.

Así las cosas, cualquier empresa que facilite dispositivos electrónicos para la realización de su trabajo deberá llevar a cabo una evaluación que permita valorar los riesgos que entrańa para la salud de sus empleados y que proporcione la información necesaria para que el empresario esté en condiciones de tomar una decisión apropiada sobre la necesidad y el tipo de medidas que deben adoptarse. De no haberse evaluado los puestos de trabajo que requieren un uso intensivo de tecnología, con la aprobación del derecho a la desconexión se deberá proceder a su realización, dejándose constancia documental a efectos de un ulterior control por parte de la Inspección de Trabajo (arts. 23 LPRL y 7 RSP).

\footnotetext{
${ }^{96}$ En este sentido, Pérez de los Cobos, F. también entiende que en el protocolo empresarial "no se trata ya de modular el ejercicio del derecho, cuanto de poner en práctica una política empresarial que facilite y promueva su ejercicio" [Cfr. Poderes del empresario..., ob. cit., p. 10/13].

${ }^{97}$ En contra, se ha considerado que la autonomía de la voluntad supone un anclaje regulador insuficiente - Alemán PÁEz, Francisco. El derecho de desconexión digital, ob. cit., p. 22/29.
} 
Una vez realizada la evaluación, se deberán definir las medidas preventivas concretas. Esto es, las modalidades de ejercicio que garantizarán el derecho a la desconexión que deben orientarse a eliminar, reducir o controlar el riesgo de fatiga informática y que serán objeto de una adecuada planificación por el empresario mediante la asignación de responsables y recursos para su ejecución, debiendo realizarse un seguimiento adecuado. En concreto, deberá elegir y/o diseñar qué acciones se llevarán a cabo para evitar una constante conectividad digital terminada la jornada laboral. Al respecto, los principios preventivos previstos en el art. 15 LPRL servirán como pautas de comportamiento para optar por las medidas adecuadas: evitar el riesgo de fatiga informática, evaluar y reducir aquellos riesgos que no puedan evitarse, tener en cuenta la evolución de la técnica, instruir a los trabajadores, etc. Desde esta óptica sí que puede entenderse una preferencia por las medidas de protección colectiva frente a las individuales, de manera que puede implicar anteponer cualquier medida impeditiva (ej. bloqueo automático de las comunicaciones, desvío de correos y llamadas...) sobre cualquier otra que requiera la voluntad del trabajador para garantizar su propio derecho a la desconexión. De nuevo aquí cabe insistir en la importancia de la intervención de la negociación colectiva para equilibrar intereses y evitar una aplicación excesivamente rígida.

También forman parte inexcusable del contenido del protocolo las acciones de formación y sensibilización para los trabajadores en relación con el mal uso de los dispositivos digitales que como hemos visto se conecta con el deber empresarial de prevención de riesgos laborales. Por tanto, estas acciones deben realizarse conforme a lo dispuesto en los arts. 18 y 19 LPRL.

La formación preventiva debe ser teórica y práctica; suficiente y adecuada; adaptada al trabajador, al puesto de trabajo y a la evolución de los riesgos; tanto inicial (en la contratación) como posterior (cuando haya cambios en las funciones, los equipos de trabajo o se introduzcan nuevas tecnologías) y periódica si fuera necesario. Su contenido debe orientarse a mejorar los recursos y capacidades del trabajador en relación al uso de la tecnología, facilitar la adaptación al cambio tecnológico y proporcionar mayor flexibilidad mental.

Por su parte, la sensibilización que debe realizarse con el fin de concienciar sobre la importancia de realizar un uso razonable de las herramientas tecnológicas puede enmarcarse tanto en el art. 18 como en el art. 19 de la LPRL, en la parte concerniente a la información en materia de prevención de riesgos laborales. Respecto a esta última dimensión, la empresa debe procurar que los trabajadores sean conocedores de los riesgos para seguridad y salud que puede entrañar el uso de las tecnologías y de las medidas y acciones de prevención y protección implementadas para prevenirlos. De este modo, se debe advertir sobre el impacto y consecuencias de la tecnología sobre la salud laboral, informar sobre las estrategias organizacionales e individuales de prevención o protección frente a los riesgos laborales que puede ocasionar y concienciar sobre buenas prácticas en el uso de dispositivos digitales.

En otro orden de cosas, el propio art. 88.3 LOPDP se refiere de forma expresa y específica a dos colectivos por motivos diversos.

Por un lado, se extiende también a los directivos. Se ha dicho que "la norma hace una referencia, quizá innecesaria, dado el carácter universal del derecho, pero probablemente útil a efectos "didácticos", a que la política interna deber ir dirigida también a los directivos, normalmente más hiperconectados y con mayores dificultades para la desconexión, en parte debido a su propio rol en la empresa o a la asunción de determinadas responsabilidades"98. Siendo cierto, no debe olvidarse que las campañas de información y sensibilización destinadas a los directivos y mandos intermedios han de educar en la necesidad de no contactar a los trabajadores por estos medios fuera de los supuestos en los que se habilite negocialmente en atención a la naturaliza y objeto de la relación laboral. Pero además de este rol del directivo en torno a la desconexión como sujeto activo que puede

${ }^{98}$ Cfr. Igartua Miró, María Teresa. El derecho a la desconexión..., ob. cit., p. 68. 
ayudar o dificultar su disfrute, a nuestro juicio la norma también está pensando en él como sujeto pasivo, titular del derecho a la seguridad y salud que pretende garantizarse mediante la desconexión digital. Y es que, cabe recordar que aquellos directivos cuya relación quede comprendida dentro del ámbito de aplicación del Real Decreto 1382/1985, de 1 de agosto, por el que se regula la relación laboral de carácter especial del personal de alta dirección ${ }^{99}$, quedarán excluidos con frecuencia del campo de aplicación de los convenios colectivos, razón por la cual debe instruirse también cierta protección por parte de la empresa, deudora de seguridad.

Y por otro lado, el protocolo empresarial ha de tener especialmente en cuenta el derecho a la desconexión digital en aquellos casos en que toda o parte de la prestación laboral toda se realice a distancia, así como en el domicilio del empleado. En especial, los casos de teletrabajo, habida cuenta de que, además de una mayor exposición a los mencionados riesgos por la propia naturaleza de su trabajo, pueden sufrir cierta monitorización por parte de la empresa mediante las TIC que sí que puede comprometer su derecho a la privacidad o incluso a la intimidad ${ }^{100}$, además de que suelen quedar al margen de las acciones formativas e informativas de las empresas y, en general, de prevención, a pesar de lo dispuesto en el art. 19.4 ET. Es necesario que en estos supuestos se exprese de modo conveniente el derecho a la desconexión y las medidas a realizar para prevenir los riesgos laborales derivados de la hiperconectividad.

\section{Régimen sancionador}

Respecto al régimen sancionador cabe destacar la ausencia de un régimen específico. No obstante, podría plantearse si los incumplimientos en esta materia encuentran acomodo entre las infracciones laborales ya existentes en la normativa general.

Respecto al inexistente régimen sancionador específico, como ya pasó con la legislación france$\mathrm{sa}^{101}$, constituye el principal punto débil de la normación española del derecho a desconexión digital. De hecho, parte de la doctrina ha considerado que, precisamente, su configuración como un derecho y no como una obligación empresarial constituye un problema de enfoque que obstaculiza su efectividad al no llevar aparejada la tipificación de conductas empresariales sancionables que permitan alcanzar el objetivo planteado ${ }^{102}$. Podría argumentarse en contra que todo derecho para el trabajador supone una correlativa obligación para el empresario, pero aun así llama la atención que el legislador orgánico ha incluido este derecho dentro del Título X de la LOPD, justo después del Título IX (Régimen Sancionador) que recoge las infracciones y sanciones para los derechos regulados en los títulos anteriores, pero ninguna para los derechos regulados en los preceptos posteriores. Por tanto, a la luz de la ubicación sistemática dentro de la norma, no puede considerarse que se deba a un olvido.

Pero lo cierto es que la LOPDP no es la norma adecuada para regular las infracciones y sanciones que se producen en el orden social, sino que un eventual régimen disciplinario para el empresario infractor habría pasado por modificar la LISOS e incluir una infracción específica por el incumplimiento de este deber, lo que además permitiría la actuación de la Inspección de Trabajo con el fin de sancionar y prevenir estas conductas. Esta intervención normativa, que ha sido defendida por quienes se han acercado al estudio de la materia, contaba con concretas propuestas

\footnotetext{
${ }^{99}$ BOE n. ${ }^{\circ} 192$ de 12-05-85.

${ }^{100}$ NTP 1123: Las Tecnologías de la Información y la Comunicación (TIC) (II)..., p. 3.

${ }^{101}$ Cialti, Pierre-Henri. El derecho a la desconexión..., ob. cit., p. 180 y ss. No obstante, considera el autor que "el establecimiento de una sanción para el incumplimiento del derecho a la desconexión podría resultar superfluo" en la medida en que tanto el respeto a los tiempos de descanso como la obligación del empresario de velar por la salud de los trabajadores ya cuentan con un "régimen protector suficiente". De esta manera, el derecho a la desconexión "se presenta como una variable de apreciación explícita" de aquellos.

${ }^{102}$ Lahera Forteza, Jesús, 2019. ¿Es solo márketing..., ob. cit.
} 
de inclusión de infracciones, bien entre las materias sancionables previstas en la subsección $1^{\text {a }}$ del capítulo II (infracciones en materia de relaciones laborales individuales y colectivas) o en la sección $2^{\text {a }}$ del mismo capítulo (infracciones en materia de prevención de riesgos laborales), aunque ninguna de ellas fue acogida por el legislador.

Por lo que nos llevaría a la segunda cuestión planteada: ¿podría sancionarse con los tipos de infracciones laborales existentes? Entre el catálogo de conductas sancionables en la LISOS, podría subsumirse una eventual conducta empresarial contraria al derecho a la desconexión en el art. 7.5 LISOS que tipifica como infracción grave la transgresión de las normas y los límites legales o pactados en materia de tiempo de trabajo (jornada, horas extraordinarias, descansos, etc.). No obstante, la falta de concreción de esta infracción y la ubicación del derecho dentro del art. 20.bis ET y no dentro de los preceptos destinados a la regulación del tiempo de trabajo, podrían dificultar su aplicación. De hecho, únicamente podría ser aplicable en la medida en que ya lo habría sido antes del reconocimiento del derecho, entendiendo que no se respetan tales límites cuando se invade digitalmente el tiempo de descanso. Podrían haber encontrado acomodo los actos empresariales que vulneren el derecho a desconectar digitalmente de sus empleados en el art. 7.10 LISOS si la opción legislativa por su ubicación sistemática hubiese sido otra, en la medida en que el mismo tipifica como infracción grave "los actos $u$ omisiones que fueren contrarios a los derechos de los trabajadores reconocidos en el articulo 4 de la Ley del Estatuto de los Trabajadores, salvo que proceda su calificación como muy graves, de acuerdo con el artículo siguiente".

Por otro lado, se podría cuestionar la aplicación del art. 8.11 LISOS que prevé como infracción muy grave los actos del empresario contrarios al respeto la intimidad y dignidad del trabajador. Aunque, como hemos indicado con serias dudas sobre si el derecho a la desconexión guarda tan estrecha relación con dichos derechos fundamentales como para precipitar la aplicación de esta infracción. Y, además, debe tenerse en cuenta que la conducta empresarial lesiva debería adquirir una entidad suficiente, difícilmente apreciable en el mero envío de comunicaciones y, sobre el que, a priori, el trabajador tiene reconocido -ahora- el derecho a no responder.

Es en lo referente a las infracciones en materia de prevención de riesgos laborales donde encontramos diversos tipos que podrían dar cabida a sancionar de forma efectiva una mala praxis en materia de desconexión digital. Para empezar, la no adopción del protocolo interno puede suponer una infracción leve tanto porque supone una omisión de un deber en materia de prevención de riesgos laborales (art. 11.4 LISOS) como por la omisión de la obligación formal o documental en que debe materializarse (art. 11.5 LISOS). En ambos casos, prevé el legislador que se aplicará dicha infracción leve salvo tenga trascendencia grave para la integridad física o la salud (circunstancia francamente difícil, a menos que pueda dar lugar a situaciones constitutivas de acoso) o que la obligación documental sea constitutiva de infracción grave o muy grave.

Por lo que respecta a las infracciones graves son varias las que pueden ser aplicables. No llevar a cabo la evaluación del riesgo psicosocial de fatiga informática cuando se utilicen dispositivos digitales, así como sus actualizaciones, revisiones y controles cuando la misma evaluación lo haga aconsejable y no aplicar las medidas preventivas que pudieran deducirse de sus resultados podría dar lugar a aplicar el art. 12.1 LISOS. De la misma manera que no registrar y archivar tales resultados ex art. 12.4 LISOS o incumplir con la planificación de la actividad preventiva que derive de la evaluación ex art. 12.6 LISOS en materia de desconexión puede ser constitutiva de infracción grave.

Por su parte, el concreto mandato de que la política interna prevea ciertas acciones formación y sensibilización orientadas a la prevención del riesgo de fatiga informática también puede desencadenar algunas infracciones. Así, el art. 12.8 LISOS prevé que es infracción grave el incumplimiento de las obligaciones en materia de formación e información suficiente y adecuada a los trabajadores acerca de los riesgos del puesto de trabajo susceptibles de provocar daños para la seguridad y salud. 
Formación que no solo deben percibir los trabajadores ocupantes del puesto de trabajo, sino que los trabajadores designados para las actividades preventivas y los delegados de prevención también deben recibir en relación a este riesgo psicosocial emergente pudiendo, en caso contrario, sancionarse conforme al art.12.12 LISOS.

Misma calificación tendría incumplir el trámite de audiencia en la realización del protocolo con los delegados de personal (art. 12.11 LISOS).

Ahora bien, la posibilidad de sancionar todas estas infracciones en materia de prevención de riesgos laborales debe superar un obstáculo. Y es que la mayoría de los preceptos citados, en su tenor literal, contiene referencias expresas a obligaciones fijadas "en la normativa de prevención de riesgos laborales" o "con el alcance y contenido establecidos en la normativa de prevención de riesgos laborales". No obstante, consideramos que se trata de un obstáculo que podría salvarse sin demasiadas dificultades, habida cuenta de la clara naturaleza preventiva que tiene el art. 88.3 LOPDP. Es, a nuestro juicio, una verdadera norma en materia de prevención de riesgos laborales, aunque no se encuentre inserta en dicho cuerpo normativo. Tiene, como ya dijimos, un carácter extrasistemático, por lo que la Inspección de Trabajo en el marco de un procedimiento sancionador o los tribunales ante un procedimiento judicial, deberían realizar una interpretación teleológica y finalista de la norma para permitir la aplicación de dichas sanciones y rechazar una interpretación restrictiva por la cual se prive al derecho a la desconexión digital de un régimen sancionador eficaz.

\section{Consideraciones finales}

A lo largo de este estudio se ha realizado una reconstrucción del régimen jurídico de la desconexión digital. Dejando de lado algunos debates doctrinales como su configuración como derecho u obligación, o si constituye o no un nuevo derecho, la tesis principal que defendemos en este trabajo es que la determinación de los bienes jurídicos protegidos con esta nueva garantía permite proporcionar una interpretación constructiva que no vacía la nueva regulación de contenido y eficacia. A nuestro juicio, el legislador español -así como el francés- ha pretendido garantizar con la desconexión digital el derecho al disfrute del tiempo de no trabajo; la conciliación de la vida privada, familiar y laboral; y la seguridad y salud de los trabajadores frente a los efectos nocivos que puede tener el uso de dispositivos digitales de forma habitual.

En este sentido, consideramos que el artículo 88 LOPDP contiene tres normas que responden a tres fines diversos. El apartado primero reconoce el derecho para todos los trabajadores y empleados públicos sin excpeciones, lo que supone un refuerzo a las instituciones tradicionales conexas cuya eficacia podría verse reducida por la generalización y extensión de las NTICs. Así, ni tendrá eficacia una orden empresarial directa que impida al empleado desconectar, ni podrá este último ser sancionado por no obedecerla. Por tanto, nos alejamos de aquellas opiniones que califican el derecho como vacuo ante la inacción de la negociación colectiva. Como ya se ha dicho, el derecho lo reconoce la ley y la norma pactada debe prever acciones y herramientas concretas que permitan un ejercicio eficaz de la desconexión digital tomando en consideración las peculiaridades de la actividad profesional. Así mismo, tampoco es necesaria una mayor labor de conceptualización del derecho para su ejercicio, pues no hay dudas sobre el verdadero significado de desconectar digitalmente. Pero, de efectuarse tal conceptualización en la negociación, lo recomendable sería que se hiciese desde la óptica de la conducta empresarial, remarcando y acentuando el deber de abstención y de garantizar el pleno disfrute del tiempo de descanso de los empleados.

Es más, la llamada a la negociación colectiva que efectúa el apartado el art. 88.2 LOPDP se hace precisamente para flexibilizar la regulación del derecho y adaptarla a las necesidades empresaria- 
les y de los trabajadores. Pues es la autonomía colectiva la que puede modular su disfrute atendiendo a la naturaleza y objeto de la relación laboral. Esta posibilidad no se le reconoce legalmente al protocolo interno elaborado por el empresario, habida cuenta de que no es un instrumento enmarcado en la autonomía de la voluntad de las partes. Por tanto, en caso de no actuar el convenio, no se puede llevar a cabo esta aplicación flexible y adaptada de la desconexión unilateralmente por la empresa.

Y es que el apartado segundo y el apartado tercero del art. 88 LOPDP responden a distintas lógicas. Mientras que el segundo conecta con las instituciones reguladoras del tiempo de trabajo (tiempo de no trabajo y conciliación) y por ello atribuye tal papel de intervención a la negociación colectiva, el tercero es una norma en materia de prevención de riesgos laborales (seguridad y salud laboral). Como tal, esta última debe de interpretarse a la luz de los mandatos de la LPRL y su normativa de desarrollo. Dicha interpretación exige que el empresario adopte todas las medidas que resulten necesarias para eliminar o minimizar el riesgo de fatiga informática. Consideramos que, pese a estar ubicada fuera de este cuerpo normativo, esta es la principal contribución de la regulación de la desconexión digital. Por primera vez, el legislador laboral aprueba una previsión expresa y específica en materia de prevención de riesgos psicosociales, que tiene carácter obligatorio y vinculante y que deberán implementar todas las empresas cuya actividad requiera el uso de dispositivos digitales por sus empleados.

Con esto no queremos decir que la regulación abordada por el legislador orgánico sea perfecta. Podrían haberse realizado pequeños ajustes en la normativa preexistente para reforzar su ejercicio, como contemplar instrumentos para que las partes necesariamente negocien esta materia en el convenio colectivo o reformar algunos aspectos de regulación de la jornada, en especial la creación de un sistema de registro de la jornada que permita determinar con claridad los tiempos en que debe producirse la desconexión digital. En esta materia, el Gobierno ha puesto fin a las discrepancias judiciales sobre el registro diario de la jornada protagonizado por la Audiencia Nacional, el Tribunal supremo y en última instancia el Tribunal de Justicia de la Unión Europea, mediante la inclusión en el art. 34 ET de un nuevo apartado 9 (art. 10 Real Decreto-ley 8/2019, de 8 de marzo, de medidas urgentes de protección social y de lucha contra la precariedad laboral en la jornada de trabajo) que obliga a las empresas a garantizar el registro diario de la jornada. Cómo se hará dicho registro queda a expensas de la negociación colectiva, el pacto de empresa o, en su defecto, de una decisión empresarial al respecto, con la garantía de cumplimiento que implica incluir en art. 7 de la LISOS una sanción específica por transgresión de las normas sobre registro de jornada. Así como el legislador también podría declarar expresamente el carácter preventivo del art. 88.3 LOPDP para garantizar que, desde el principio, su elaboración por parte de la empresa se realice de forma integrada en el plan de prevención de riesgos laborales. Así como facilitar la aplicación de las sanciones previstas en la LISOS.

En fin, la regulación de la desconexión digital tampoco puede desligarse del teletrabajo. Su relación con las materias ordenadoras del tiempo de trabajo y la especial vulnerabilidad de estos trabajadores frente a los riesgos psicosociales requieren un tratamiento normativo específico. A mayor abundamiento, tras los últimos acontecimientos en los que se ha producido un salto cualitativo y cuantitativo del recurso al teletrabajo al que se han visto abocadas muchas empresas para evitar una paralización total de sus actividades. Quién sabe si esta transformación de puestos de trabajo presenciales en teletrabajadores -en principio excepcional y extraordinaria- pueda suponer un avance clave y un punto de no retorno al estado precedente en la denominada digitalización o revolución 4.0 que tanto se estaba resistiendo.

Con todo, en la medida en que hay una reforma laboral en ciernes, se abre una nueva ventana de oportunidad para realizar estos ajustes e incluir estos aspectos en la normativa laboral. 